FREDERICK H. ABERNATHY

Harvard University

JOHN T. DUNLOP

Harvard University

J A N ICE H. HAMMOND

Harvard Business School

DA V ID WEIL

Boston University School of Management

\title{
The Information-Integrated Channel: A Study of the U.S. Apparel Industry in Transition
}

THE POPUlAR PROGNOSIS for the U.S. apparel industry is bleak. Citing increased import penetration in many product segments and the concurrent erosion of domestic employment, many analysts regard apparel manufacturing in the United States as a dying industry. ${ }^{1}$ The Department of Labor concurs, projecting a significant reduction in employment in the domestic apparel industry during the next decade. Under its most optimistic scenario, the department predicts employment will drop from a 1990 level of 839,000 to 649,000 in 2005; under its most

Funding for this paper was provided by the Alfred P. Sloan Foundation. We are grateful to Tim Bresnahan, Richard Caves, Peter Doeringer, Oliver Hart, Peter Pashigian, and Peter Reiss for their comments on earlier drafts of this paper. We thank Katy George and Igor Choodnovskiy for their superb research assistance.

1. For example, Alan Blinder writes: "to remain a rich, high-wage nation, we must keep changing our industrial structure. We must let the routine industries that can thrive with unskilled labor migrate to poorer countries in Asia, Latin America, and even Eastern Europe, and we must concentrate instead on the complex, progressive tasks that require highly skilled workers. . . . This approach . . . will surely be bad news for both labor and capital in certain industries - as it already has been for, say, textiles and steel." Blinder (1992, pp. 13-14). 
pessimistic scenario, employment is projected to fall to 479,000 in $2005 .^{2}$

The arguments underlying this prognosis generally proceed in the following manner: apparel is an industry driven by price-based competition among generally small manufacturing establishments. ${ }^{3}$ U.S. wage levels greatly exceed those of competitors in countries such as the People's Republic of China and Mexico. Because domestic wages are too high relative to the labor productivity of U.S. apparel workers, U.S. manufacturers operate at a significant cost and therefore competitive disadvantage. As a result, U.S.-based apparel manufacturers face a bleak future.

This view oversimplifies the nature of competition in the apparel industry. Competitive dynamics in many segments of the industry are being transformed by technological innovations that allow the low-cost collection, processing, and dissemination of consumer sales data. These innovations lay the foundation for a new set of retailing strategies directed at reducing a retailer's exposure to market demand risk by using daily, point-of-sale information to adjust the supply of products offered to consumers at retail outlets to match actual levels of market demand. The new retailing strategies, in turn, lead to apparel supplier investments in the information technologies required to respond to realtime order requests. In the short term these developments may merely shift inventory costs backward to apparel manufacturers. In the long run, however, adoption of information-based and related practices by retail suppliers will raise the productivity of capital for the retail-appareltextile supply chain as a whole by reducing overall levels of inventories.

The manufacturing capabilities required to respond in this information-integrated manner in many cases challenge the way apparel firms are structured internally and how they interact with their suppliers (especially textile firms). Specifically, these lean retailing strategies place pressure on apparel manufacturers to adopt information systems, order fulfillment practices, distribution practices, and related services that allow them to fill retailers' orders rapidly, efficiently, and flexibly. The new retailing strategies also place manufacturers under greater burden

2. Bureau of Labor Statistics (1992), p. 57.

3. In 1991 an average apparel manufacturing establishment employed 41 employees; the average was 155 in men's and boys' wear establishments and 29 in women's wear. Bureau of the Census (1994, table 1b). 
either to hold more finished goods in inventory or to innovate production processes to meet retailer requirements and reduce their own exposure to risk. Risk-reducing innovations by apparel manufacturers in turn change the planning and production requirements of their textile suppliers. Thus, the changing dynamics of the apparel industry must be analyzed in the context of the retail-apparel-textile supply channelthat is, the sequence of firms encompassing textile suppliers, apparel manufacturers and retail stores. ${ }^{4}$

The long-term competitive performance of the firms responsible for the production and distribution of apparel products will therefore be shaped by their capabilities to respond rapidly to consumer demand while minimizing exposure to inventory risk. This fact potentially places a premium on such characteristics as geographic proximity to market; technological sophistication in planning, distribution, and production; and investment in closer, longer-term relationships with the other players in the channel. Because success in the apparel industry has been characterized over the last three decades by almost the opposite attributes, this analysis implies that an information-integrated U.S. apparel industry may be far more viable than the industry depicted in the popular prognosis.

This paper analyzes the transformations in process in the retailapparel-textile channel, exploring both economic forces leading to the channel's historical organization and recent forces that are blurring distinctions between production stages in the channel. The analysis draws on a new set of industry data based on a comprehensive questionnaire of a large cross-section of U.S. apparel manufacturers. The questionnaire provides data at the business-unit level on historical and current practices within apparel firms and among retail-apparel-textile channel partners, and it includes data on a range of performance outcomes.

The empirical results indicate that apparel suppliers have dramatically increased their investments in information technologies, distribution systems, and other associated services during the same period that lean retailing practices have grown. In addition, the analysis reveals

4. In practice, manufacturers of such items as fiber, buttons, and zippers are also important supply channel constituents. Here, for purposes of simplification, we focus on the three levels in the channel-retail, apparel, and textile - that are undergoing the greatest change. 
that those firms under greatest pressure by lean retailers have been the most likely to make such investments and to a lesser extent, to invest in innovations in other stages of manufacturing. Finally, the empirical evidence suggests that those firms that have invested in major innovations in their manufacturing operations perform much better along a number of dimensions than those that have done little to innovate production beyond providing basic links to lean retailers.

\section{Historical Drivers of the U.S. Apparel Industry}

The channel discussed in this paper is a sequence of firms extending from cotton growers and sheep ranchers at one end to retail stores and, ultimately, consumers at the other end. This sequence of firms can be thought of as a production channel of linked industries providing consumers with a wide range of apparel products. Before we develop this concept further, it is useful to examine the historical drivers of the apparel production channel to frame the developments that are currently transforming the channel.

The traditional method of studying the retail-apparel-textile channel focuses on the competitive dynamics at each stage of production (specifically, retailers that sell apparel products; apparel producers that design, cut, and sew garments; and textile suppliers that knit or weave fabric for use in apparel products). Viewing the production stages as separable has been sensible historically because arm's-length markets linked each of the stages to one another. This historical survey also shows how changes in information availability, transportation, and other technologies have affected the organization of the industry.

\section{Retail: From General Store to Mass Retailers}

The full-line and full-service wholesaler supplying the general store began to be replaced in the 1870 s and 1880 s by forms of mass retailers, including department stores, mail-order houses, and chain stores. Railroads, telegraph, steamships, and improved postal services facilitated these new enterprises, all of which had internal administrative structures that coordinated the flow of goods from a great many producers to even 
larger numbers of individual consumers. According to historian Alfred D. Chandler, Jr., this coordination reduced " the number of transactions involved in the flow of goods, increased the speed and regularity of that flow, and so lowered costs and improved the productivity of the American distribution system.",5

The rapid growth of urban centers and increased access to their downtown areas by urban transport encouraged mass retailing; the department store, which offered "one-stop" shopping through its wide range of goods or departments, was the primary response. The increasing popularity of ready-made clothing and home furnishings as well as increased newspaper advertising were contributing factors. Department stores were larger than specialty shops limited to a few items, operated on specified prices rather than individual barter, offered the convenience of returning purchases for exchange or cash, and operated primarily on a cash payment basis. They sold goods at a lower markup than specialty stores and concentrated on achieving a high level of stock turnover. Because sales were made on the store's premises rather than through traveling sales representatives, buyers had an even larger role than wholesale jobber buyers.

Following the widespread introduction of new transportation and communications systems, Montgomery Ward, formed in 1872, was the first organization to market a wide variety of consumer goods exclusively by mail. Sears, Roebuck and Company followed, outpacing Montgomery Ward in the 1890s. As in department stores, buyers for mail-order houses had full autonomy over their product lines. "Each merchandise department was a separate dynasty, and the buyer was in complete charge," Chandler wrote. ${ }^{6}$

Department stores, mail-order houses, and later grocery chain stores grew to dominate mass retailing in the century after 1880 by virtue of large volume, high turnovers of inventory, lower prices, payments in cash by customers that reduced the need for credit and debt, and the dominant role of the buyer. Buyers, Chandler noted, "purchased

5. Chandler (1977, p. 209).

6. Chandler (1977, p. 231). In the 1980s mail-order firms such as Lands' End and L.L. Bean once again had a major impact on the dynamics of the retail-apparel-textile channel by using telephone order information to better align consumer demand with supply, thereby reducing costs through inventory reduction. 
largely on the basis of past experience and their own intuitive feeling about what the customers would continue to want." ${ }_{7}$ The scale and scope of these earlier mass retailers conferred upon them competitive advantage partially because information was centralized in the hand of the buyer. A century later, the role of the buyer would be diminished by much more accurate, current, and predictive information systems.

\section{Apparel: From Homework to Modern Manufacturing}

In the early days of the ready-made clothing industry, cloth was cut and assembled into bundles of parts to be given to workers to sew at home and then returned for finishing operations. Even today some product lines utilize homework, and others send bundles of cut cloth under the trade laws to Caribbean Basin firms for sewing.

The invention of the sewing machine (by Howe and Singer) in the mid-1800s, the need for Civil War uniforms, and the introduction of a standardized body-size measurement system enhanced factory production at the expense of homework. In 1880 less than half of men's suits were ready-made; by 1920 the customary garb of adult males was factory-made. Long vertical electric cutting knives replaced cutting shears; faster, electrically driven sewing machines were devised; and pressing machines were developed.

Enterprises in the apparel industry have taken one of three general forms - the manufacturer with an inside shop, the jobber, and the contractor that is an outside shop. A manufacturer may also utilize one or more contractors that constitute outside shops. The jobber, characteristic of the women's clothing segment, tends to concentrate on merchandising the finished product. While a jobber may therefore purchase cloth and materials, design or purchase designs of garments, and cut or contract out the cutting of fabrics, the jobber turns over the sewing and assembly of garments to other contractors.

This manufacturer-jobber-contractor system provides great flexibility with fluctuations in style, season, and economic conditions. It also separates and specializes the functions of production, material purchasing, and selling of the finished product. Capital per worker in apparel firms is very low-approximately $\$ 2,000$ in 1992 ; entry and exit take place frequently; workplaces are small; and labor costs constitute a large

7. Chandler (1977, p. 238). 
share of expenses. In this setting employees in sewing operations have historically been compensated on a piece-rate method of pay, so that the sum of such piece rates provides the total direct labor costs for sewing a garment.

Historically, after being cut from patterns, the parts of garments are distributed in tied bundles to operators for sewing (in either contract shops or in-house plants). Each operator in the traditional system specializes in one, or a few, operations. ${ }^{8}$ To sew a dress shirt, for example, under the bundle system requires twenty to forty different operations. The aggregate labor time actually required to perform all the separate sewing operations in a single shirt would typically be less than twenty minutes. To allow maximal productivity of workers and minimal threats of disruption, however, the bundle system suffers from large work-inprocess inventories that buffer each individual operation as the cut bundles move through the sequence of sewing, pressing, and packing operations. Thus, a single dress shirt with less than twenty minutes of actual labor content would require as much as six weeks of elapsed time from cutting to becoming a packaged product. The costs of having large work-in-process inventories include both capital costs and time delays that constrain flexibility to respond to changing demand patterns. The proliferation of materials, styles, colors, and stripes and other prints increased the costs of inventory considerably. In an environment characterized chiefly by price-cost competition, such inventories were a cost of doing business borne by manufacturers (as they were for the early retailers).

\section{Textiles: From Fiber to Cloth and Product}

Primary textile manufacturing includes both the spinning of raw cotton and other fibers into yarn and the weaving or knitting of yarn into "greige" goods (unfinished cloth). Although specialized spinning and weaving mills still exist, the great majority of enterprises engage in both operations. Much of the cloth produced in weaving mills requires further finishing such as bleaching, shrinking, dyeing, and printing before it is ready for sale to the apparel industry or to retail distributors. Historically, finishing operations have been undertaken by separate firms known as converters, which played a large role in the

8. Stone (1938). 
design and styling of finished goods. The primary spinning and weaving facilities of the textile industry involve substantial capital (approximately $\$ 300,000$ ) per worker.

Over the years, several textile enterprises extended their operations forward into converting operations, and several converters extended their operations backward into primary textiles. Furthermore, some textile companies have integrated operations that specialize in particular products that are ready for retail sale such as finished sheets and pillow cases or towels. ${ }^{9}$

Apparel usage has historically dominated the consumption of fiber and textile output. By the early 1990s, however, that dominance had waned: apparel's share of fiber consumption was 38 percent; home furnishings 16 percent; floor covering 21 percent, and industrial textile products 24 percent of fiber production. Although the textile industry has been regarded as highly competitive and unconcentrated, considerable concentration occurs in particular product lines. The industry has experienced several periods of substantial integration, horizontal mergers, and conglomerate groupings. In the 1930s and again in the 1980s, the industry underwent considerable restructuring, and some product lines became more concentrated. ${ }^{10}$ Currently, the four largest firms control about 40 percent of weaving and yarn mill output. ${ }^{11}$ Finishing and dyeing plants and knitting mills are typically smaller firms with larger numbers of competitors.

The concentrated nature of segments of the industry and the moderate share of industry consumption represented by apparel has meant that relations between apparel manufacturers and textile suppliers have been at arm's length and price-driven. Efforts by apparel manufacturers to find low-cost sources of textiles for their products (in combination with similar sourcing strategies by retailers and wholesalers) led to increases in offshore sourcing. ${ }^{12}$ Textile imports grew by more than 12 percent a

9. Knitted goods are a growing segment of the textile industry. The warp knitting machine produces a flat fabric much like a woven fabric and the circular knitting machine produces a tubular fabric. The most important knit goods are hosiery, knit underwear, and knit outerwear. Knitting mills now account for almost 30 percent of the production employees in textile mill products (Bureau of Labor Statistics, 1991).

10. Office of Technology Assessment (1987, p. 61).

11. Chaykowski, Thomason, and Zwerling (1994, p. 375).

12. As in the case of the apparel industry, the Multi-Fiber Agreement, along with 
year annually between 1976 and 1988, while the domestic market grew at less than half that rate. ${ }^{13}$

\section{Relations among the Three Segments}

Historically, the firms within the retail-apparel-textile channel related to each other largely through selling and buying staff. Conventional markets characterized the relationships between textile and apparel enterprises (and other purchasers); apparel enterprises and retail establishments; and retailers and consumers. It is significant that, although considerable consolidation has taken place within each of these three segments, few, if any, woven-textile enterprises historically entered the apparel business, and few apparel manufacturers-with notable exceptions such as Hartmarx in men's clothing and most recently, Levi Strauss-entered retailing.

\section{Lean Retailing and Channel Integration}

Channel dynamics are increasingly affected by technologies that allow retail firms and their suppliers to track actual consumer sales on a real-time, store-by-store, stockkeeping-unit level basis. (A stockkeeping unit, or SKU, is the most detailed level of product specification. $)^{14}$ This capability has provided a foundation for lean retailing, which requires a retailer to match closely consumer demand and retail supply at the SKU-level while minimizing retailer inventory. ${ }^{15}$ Done well, this

negotiated bilateral agreements, have been the mechanisms to regulate trade among countries; see Cline (1987, pp. 145-68).

13. Chaykowski, Thomason, and Zwerling (1994, p. 379).

14. For apparel products, an SKU is a unique product with a specified manufacturer, color, fabric, style, and size. An example of an SKU is a white, pinpoint oxford cloth, men's button-down dress shirt, size 16" (collar)-35" (sleeve), manufactured by a specific company.

15. The term lean retailing used throughout this article refers to a cluster of interrelated practices undertaken by retail channels to achieve the objective of matching consumer demand and retail supply. Although this objective requires retailers of all types to undertake several core practices, the methods and extent of implementing these strategies are not uniform and in fact differ across retail channels. For example, WalMart Stores pioneered this type of retailing strategy for mass merchants, focusing on providing a narrow collection of basic apparel products with minimal inventories through the collection and centralization of store-level sales data. Mail-order retailers such as 
strategy allows lean retailers to offer consumers greater product variety and higher product availability at lower costs. As the benefits associated with lean-retailing strategies become apparent and the costs of necessary systems fall, more retailers are adopting such strategies as a basis for competition.

This section begins with a description of the data used throughout the rest of the paper. It then describes the components of lean retailing and describes how these practices change the flow of information within the channel. It then presents a model of the effects on channel inventory levels that result from this infusion of information. Finally, the section builds on these insights and draws on economic theory to create a framework for analyzing changes in the practice and performance of apparel suppliers as lean retailing becomes more pervasive.

\section{Data}

This study relies on a new data set providing comprehensive information on a wide range of practices and channel relations at the business-unit level. A business unit is defined as the lowest level of a firm with responsibility for formulating annual policies dealing with merchandising, planning, manufacturing, distribution, and related activities for a product line or lines and that collects financial data for those activities. For some organizations, the business unit may be the overall corporation. For others, several business units might operate under a single corporate umbrella. A business unit may rely on one (or more) in-house plant(s), a network of contractors (with either domestic or foreign operations), or both to produce its products.

Data for each business unit were collected for a comprehensive set of performance and practice outcomes as well as for other background characteristics. These include detailed data concerning information, sales, and design links with retailers; manufacturing, sourcing, and distribution practices; and a wide variety of performance measures, both traditional (for example, operating profits and sales growth) and nontraditional (such as product development and replenishment lead times

Lands' End have developed related strategies, but their access to accurate demand data (for a more diverse line of higher-end products) is through data from phone sales. More recently, retailers such as Dillard's have applied "lean" principles to their department stores, which sell a far more diverse and fashion-oriented set of apparel products than mass merchandisers. 
and order fulfillment rates). The sample consists of 118 business units representing 84 separate companies; data were collected for 1988 and 1992. The appendix to this article describes detailed information on the survey's development, distribution, and response rates and on the representativeness of the sample. The sample includes approximately 30 percent of the total value of domestic shipments of apparel products (see appendix).

\section{Elements of Lean Retailing}

Technological advances have greatly enhanced the information links among firms in the apparel channel. Although changes in the competitive environment have provided strong motivation to adopt informationintensive strategies, it is only through the development of key facilitating technologies that such strategies have actually been implemented. Three areas of technological innovation have been critical to establishing greater information flows and tighter links among channel partners:

- Bar codes, bar-code scanning equipment, and related technologies, which allow rapid, automatic identification of products and packages;

- Electronic data interchange (EDI), which allows the rapid, inexpensive communication of massive amounts of data including order placement and payments;

- Automated distribution operations (including automated identification, conveyance, and sorting capabilities). ${ }^{16}$

These interrelated information-processing techniques have set the stage for the emergence of lean-retailing strategies that respond to complicated market demand patterns. The core of the lean-retailing strategy is reducing exposure to market demand risk by constantly adjusting the supply of consumer products available at retail outlets to match actual levels of market demand. Lean retailers therefore attempt to incorporate

16. None of these technologies was originally developed for use in the apparel industry. For example, bar-coding was developed and introduced in 1971-75 under an agreement between the associations of food chain stores and grocery manufacturers. Bar-coding is administered by a nonprofit organization, the Uniform Code Council (UCC), which assigns the bar-codes to particular companies. The UCC has furnished us data to study the diffusion of bar-coding throughout the economy. Bar-coding spread into the apparel and retail sector beginning in the $1980 \mathrm{~s}$. 
into their total sourcing cost functions both direct product costs (as reflected in the wholesale prices charged by suppliers) and the indirect costs associated with demand uncertainty, including costs associated with being out of stock on an item (known as stock-outs), costs of markdowns and write-offs, and inventory-carrying costs. As a result, the performance measures implied by a lean-sourcing strategy include measures such as a supplier's speed (short lead times between placing fabric orders and receiving finished goods and quick order fulfillment times), accuracy, and flexibility (ability to introduce new products) along with the historic measures related to direct costs.

A comparison of the growth in operating revenues within different retail channels reveals the rapid growth of this group of retailers. For example, Wal-Mart Stores, the consummate lean retailer, had a compound annual growth rate (CAGR) of 30.6 percent during the ten-year period from 1983 to 1993 , compared with an average CAGR of 9.72 percent among mass merchant retailers. Similarly, Dillard Department Stores, a leader in lean retailing among department stores, had a CAGR of 19.7 percent during that period, compared with 4.87 percent among comparable department stores. ${ }^{17}$

Constantly adjusting retail stock levels to market demand requires lean retailers to change their ordering practices. Instead of following traditional practices of ordering large quantities of product far in advance of the selling season and holding them in warehouse inventory until consumer demand materializes, lean retailers order a good close to its selling season, in small initial quantities, and then request product replenishment within the selling season on an as-needed basis. Lean retailers thus maximize the productivity of their inventory by holding only selling-floor inventory in necessary quantities to meet immediate customer needs.

Before the introduction of lean retailing practices, risk in the channel was managed by allowing lead times long enough for each party in the channel to produce what its purchaser in the supply channel ordered. Under this scenario, firms were not required to order raw materials or manufacture products on a speculative basis. Thus, when the retailer placed a garment order with an apparel manufacturer, the apparel manufacturer was given sufficient time to acquire the necessary materials

17. Standard and Poor's Industry Surveys (1994, p. R68). 
and manufacture the products before the specified delivery date. Similarly, upon receiving a fabric order from the apparel manufacturer, the fabric manufacturer had enough time to acquire the necessary materials and make the fabric. (These practices also typically allowed maximal efficiency of manufacturing operations as measured by direct labor and factor productivity, because orders could be batched or sequenced to minimize set-up and sequencing costs.) In this environment where action is taken only after all order information is in hand, little information beyond that order is required.

Lean-retailing practices have begun to change that pattern: a larger percentage of the product volume within the channel now arises from orders made on the basis of real-time sales. Lean-retailing suppliers are no longer able to plan the majority of their production on prespecified orders. To meet retailers' short lead-time requirements, supplying firms must make preliminary plans and commitments based on their best forecasts of demand. In this environment, the ability of a supplier to gather and analyze available data on demand patterns and to incorporate the results into internal forecasting, planning, and decisionmaking processes becomes critical to competitive performance.

Table 1 presents survey results about the frequency of product replenishment among business units in the sample, weighted by the total volume shipped in 1992 by business unit. For each of five retail channels, it reports the mean percentage of total dollar volume shipped on a daily, weekly, bimonthly, and monthly replenishment basis, as well as the percent of volume shipped on a nonreplenishment basis.

As the table reveals, the degree of replenishment activity differs dramatically by retail channel. For example, in 1992 daily or weekly replenishment shipments constituted less than 30 percent of total wholesale dollar volume shipped to department stores by the reporting business units and about 22 percent of volume shipped to specialty stores. In contrast, 73 percent of total dollar volume was shipped on a daily or weekly basis to national chains, and more than 65 percent adhered to such requirements for shipments to mass merchants. The relative growth of different retailing channels is shown in the lower portion of table 1, which compares the total wholesale dollar volume shipped (weighted by business unit shipments) for different retail outlets. The retail outlets with the highest proportion of volume on lean retailing also experienced the fastest growth between 1988 and 1992: mass mer- 


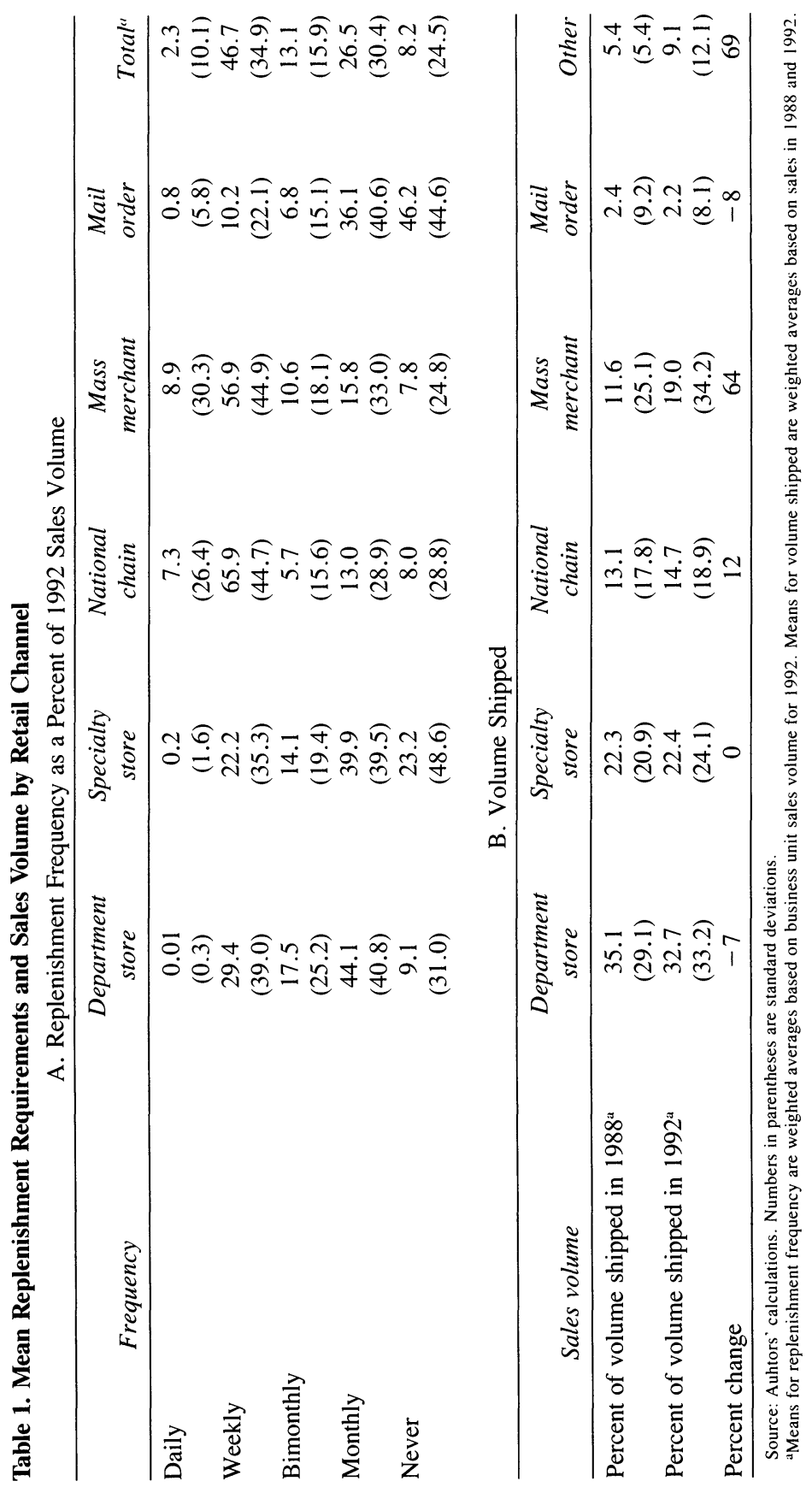


chants' shipments as a percent of all shipments increased from 12 percent to 19 percent, while national chain shipments increased from 13 percent to 15 percent.

Mass merchant and national chain channels were the earliest adopters of lean strategies for several reasons. First, the larger size of retailers in these categories facilitated adoption of rapid-replenishment practices as a result of economies of scale in such areas as information technology and inbound transportation. These economies as a basis for innovation parallel those that facilitated the emergence of department stores and mail-order houses a century earlier.

Second, both retail categories primarily sell basic apparel products..$^{18}$ These products are prime candidates for replenishment because the product style typically remains in a retailer's and apparel company's product line for a relatively long period of time, in some cases for many years. The longevity of these products provides opportunities to use information acquired during the selling season for replenishment during the same or future seasons. Basic items also represent a major percentage of all apparel goods sold: in the study sample, 45 percent of all shipments by business units (weighted by sales volume) can be classified as basic, compared with 27 percent for fashion-basic and 28 percent fashion. Thus, given their scale and product mix, it is not surprising that Wal-Mart, Kmart, and other mass merchandisers have been the most aggressive in their efforts to establish lean retailing and that J.C. Penney has been a leader among national chains. ${ }^{19}$

\section{Impact of Lean Retailing on Channel Inventory Levels}

As retailers drive down their own inventories, manufacturers in turn must make changes in their internal practices. Specifically, lean retail-

18. Product categories are defined in the survey as follows: A basic product is a style that remains in a company's product line for years; in some cases indefinitely. Examples are men's white, button-down, dress shirts and five-pocket jeans in a traditional fabric and color. A fashion-basic product is typically a variant of a basic item, having the same style and silhouette, but varying in fabric, color, finish, or trim. Fashion-basic items are offered for a limited number of seasons. An example is men's dress shirts with a distinctive striped fabric. A fashion product is a product style that has an extremely short selling life (usually one season). As a result, demand for fashion items is typically difficult to forecast. An example is junior dresses.

19. Although the first lean retailers tended to focus on basic and fashion-basic items, more recently, some retailers have adopted rapid-replenishment practices for more fashion-oriented items. 
ing requires manufacturers to provide increased product variety, shorter order-fulfillment lead times, and higher order-fill rates. Unless a manufacturer makes significant changes to its internal planning and production processes, it will be able to achieve these three capabilities only by increasing its own inventory of finished goods.

A simulation model capturing the dynamics of a manufacturing-retail order-fulfillment system can be employed to analyze how inventory levels of finished goods change as a function of increasing product variety and order fulfillment rates and decreasing lead times for filling orders. The model uses a heuristic algorithm to determine a production schedule for a manufacturing-retailing system with stated lead times, order fulfillment rates, and demand distributions. ${ }^{20}$ (In the following discussion, the term "consumer satisfaction rate" denotes the percent of all consumer demand met from a retailer's inventory, and "order fulfillment rate" denotes the percent of retailer demand (that is, retail orders) filled by the manufacturer in a specified period of time.)

Product VARIETy and InVENTORY ReQuiRements. An apparel manufacturer must design, cut, sew, package, and deliver a range of products to retail customers in the face of often significant demand uncertainty. Apparel products are perishable - if brought to market late, their value can be greatly diminished. Those holding a product after demand for the product has waned face costs associated with price markdowns, clearance sales, and liquidation.

In recent years products have proliferated in almost every apparel category. As a result the demand uncertainty previously associated only with fashion products - typically those with very short selling livesnow characterizes many items once regarded as basic products, such as men's dress shirts. Throughout much of the post-World War II era, the majority of men's shirts sold in the United States were white dress shirts. As these once-basic products have been replaced by "fancy" shirts of colored or patterned material, the market share of white shirts as a percent of all dress shirts has fallen from 72 percent in 1962 to 52

20. The model assumes that weekly demand for the SKUs follows independent and identically distributed gamma distributions; the distribution parameters are based on moments of empirical industry data for basic and fashion-basic products. (The model's results are robust even when the independence assumption is relaxed.) The model also assumes that orders are placed on a weekly basis, and that weekly production can vary between 80 and 120 percent of the plant's design capacity. For more details, see Hammond, Tang, and Abernathy (1994). 
Table 2. Product Proliferation

A. Average Number of Products Offered, 1988 and 1992

\begin{tabular}{|c|c|c|c|c|c|}
\hline \multirow[b]{2}{*}{ Number of SKUs } & \multirow[b]{2}{*}{1988} & \multirow[b]{2}{*}{1992} & \multirow{2}{*}{$\begin{array}{l}\text { Percent } \\
\text { change }\end{array}$} & \multicolumn{2}{|c|}{$\begin{array}{l}\text { Number of } \\
\text { observations }\end{array}$} \\
\hline & & & & 1988 & 1992 \\
\hline $\begin{array}{l}\text { In product line } \\
\text { in stated year }\end{array}$ & $\begin{array}{c}3,871 \\
(6,411)\end{array}$ & $\begin{array}{c}6,304 \\
(13,261)\end{array}$ & 63 & 73 & 88 \\
\hline $\begin{array}{l}\text { Introduced to product line } \\
\text { in stated year }\end{array}$ & $\begin{array}{c}2,368 \\
(4,719)\end{array}$ & $\begin{array}{c}3,688 \\
(7,257)\end{array}$ & 56 & 69 & 83 \\
\hline $\begin{array}{l}\text { Dropped from product line } \\
\text { in stated year }\end{array}$ & $\begin{array}{c}2,057 \\
(4,479)\end{array}$ & $\begin{array}{c}3,050 \\
(5,788)\end{array}$ & 48 & 68 & 81 \\
\hline
\end{tabular}

B. Average Number of Distinct Selling Seasons by Product Category, 1984, 1988, and 1992

\begin{tabular}{lcccccc}
\hline & & & & & \multicolumn{2}{c}{$\begin{array}{c}\text { Number of } \\
\text { observations }\end{array}$} \\
\cline { 5 - 8 } Product category & 1984 & 1988 & 1992 & change & 1984 & 1992 \\
\hline Fashion products & 2.9 & 3.2 & 3.7 & 28 & 65 & 80 \\
Fashion-basic products & $(1.3)$ & $(1.3)$ & $(1.7)$ & & & 79 \\
Basic products & 2.8 & 2.9 & 3.2 & 14 & 63 & 75 \\
& $(1.4)$ & $(1.4)$ & $(1.6)$ & & & 63 \\
\hline
\end{tabular}

Source: Authors' calculations. Means are based on unweighted averages for business units in the sample. Numbers in parentheses are standard deviations.

percent in 1967 to about 21 percent by $1986 .{ }^{21}$ Today, a typical jeans manufacturer's product line contains 10,000 to 20,000 different SKUs.

The trend toward product proliferation is vividly shown among the business units in the sample, as displayed in table 2 . The first row in table 2a reports the average number of SKUs per business unit, which increased from an average of 3,871 in 1988 to 6,304 SKUs in 1992. The next two rows explain the origin of this large increase. To begin with, the average number of new SKUs introduced per year by a business unit rose from 2,368 in 1988 to 3,688 in 1992. At the same time, the average number of SKUs discontinued by business units rose from 2,057 in 1988 to 3,050 in 1992. Thus, each year a large portion of each business unit's product line consists of new products with little or no relevant demand history.

Table $2 b$ shows the mean reported number of distinct selling seasons

21. Pashigian (1988, p. 943). 
in 1984,1988 , and 1992 for products classified as fashion, fashionbasic, and basic. In each category, the reported number of distinct seasons has risen, with the most dramatic increases in the most fashionable products. The increase partially explains the trend toward increased product proliferation and also shows that selling seasons are becoming shorter, making it harder to replenish products within season.

The tremendous proliferation of apparel products has a variety of implications for apparel manufacturers; one of the most significant of these is the increase in uncertainty about which of the manufacturer's many products will sell. To illustrate how increasing variety raises demand uncertainty, consider a situation in which a manufacturer offers $N$ products, each with independent, identically distributed demand distributions. ${ }^{22}$ Let $E\left[D_{i}\right], \sigma_{i}$, and $C_{v}\left[D_{i}\right]$ denote the expected value, standard deviation, and coefficient of variation, respectively, of $D_{i}$, the demand for $\mathrm{SKU}_{i}$.

Because the demand variables for the individual SKUs are identically distributed, the moments of the demand for each SKU are the same. Thus if we let $\bar{D}=E\left[D_{i}\right]$ and $\sigma=\sigma_{i}$ for $i=1, \ldots, n$, and define the total demand $T=\sum_{i=1}^{n} D_{i}$, then $E[T]=N \cdot \bar{D}, \sigma_{T}=\sigma \sqrt{N}$ (because the $D_{i}$ s are independent), and the coefficient of variation of $T$ is $C_{v}[T]=$ $\sigma \sqrt{N} / \bar{D}=C_{v}\left[D_{i}\right] / \sqrt{N}$. Thus, if the moments of the distribution for total demand are held constant, $C_{v}\left[D_{i}\right]=C_{v}[T] \cdot \sqrt{N}$, that is, the coefficient of variation of each individual SKU increases as the square root of the number of SKUs. ${ }^{23}$ (This logic follows the standard "riskpooling" argument; in this case, increasing product variety can be

22. If demand for different products is correlated or if the sales of different products are at significantly different levels, then the coefficient of variation does not rise as fast. In addition, if increasing product variety increases total sales, the coefficient of variation rises less rapidly.

23. Here we assume that increasing product variety in an environment of significant product proliferation allows a firm to maintain total sales volume, rather than increase total volume. In practice, sales may increase somewhat as new products are added, thereby reducing the impact of variety on the coefficient of variation of individual SKUs. In general we would not expect the introduction of additional products to reduce uncertainty about demand for each SKU. Under this assumption we obtain the following bounds on the coefficient of variation for an SKU when the number of SKUs increased from $N^{\text {old }}$ to $N^{\text {new }}: C_{v}\left[D_{i}^{\text {old }}\right] \leq C_{v}\left[D_{i}^{\text {new }}\right] \leq C_{v}\left[D_{i}^{\text {old }}\right]\left(N^{\text {new }} / N^{\text {old }}\right)^{1 / 2}$. 
Figure 1. Weeks of Finished Goods Inventory as a Function of Demand Uncertainty

Weeks of inventory

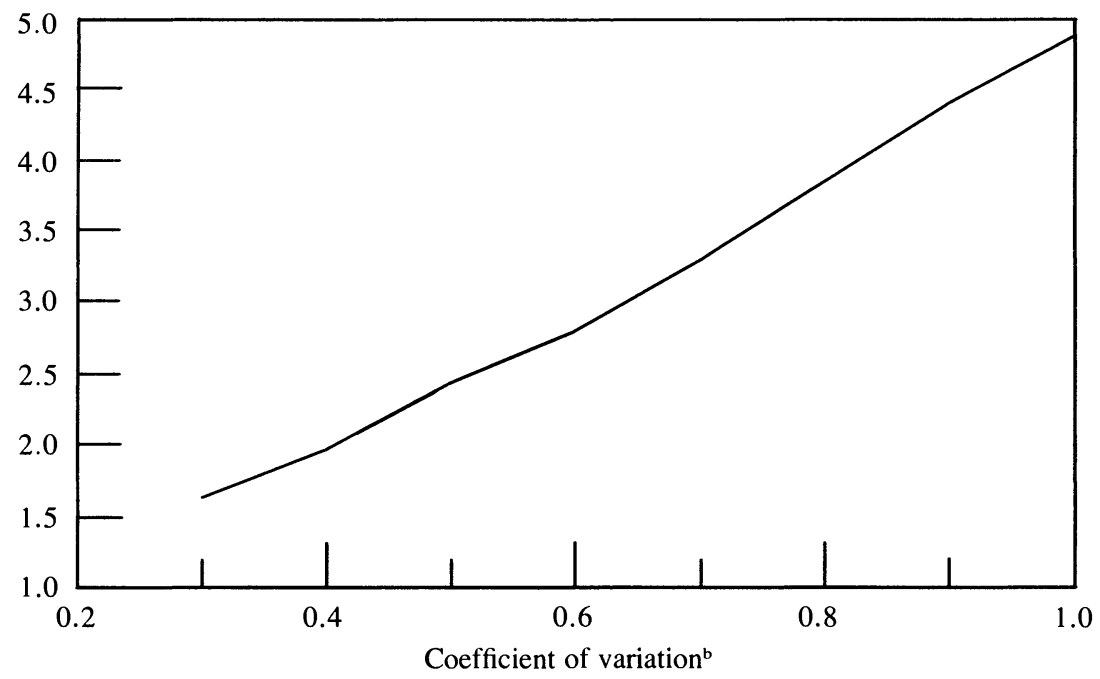

Source: Authors' calculations, assuming an order fulfillment rate of 97 percent and a lead time of three weeks. ${ }^{a}$ A verage inventory divided by average demand.

${ }^{\text {b }}$ Standard deviation of demand divided by average demand.

viewed as decreasing the ability to pool customer demand for specific products.)

Thus, retailers' and manufacturers' drive to increase market share through increased product variety has driven demand uncertainty higher for each individual product. Figure 1 shows how finished goods inventory increases as a function of the coefficient of variation of demand (or equivalently, it increases as a function of the square root of the number of products in the product line). In the figure we assume that the order fulfillment rate equals 97 percent and that the lead time needed to fill orders equals three weeks. Note that increasing the coefficient of variation from 0.5 to 1.0 (which would be associated with increasing the number of products offered by a factor of four) nearly doubles the amount of finished goods required to provide the desired service level. ${ }^{24}$

24. The parameter choices for the figures, although based on data from actual apparel firms, are intended to be for illustrative purposes only. 
Figure 2. Weeks of Finished Goods Inventory as a Function of the Order Fulfillment Rate

Weeks of inventory ${ }^{\mathrm{a}}$

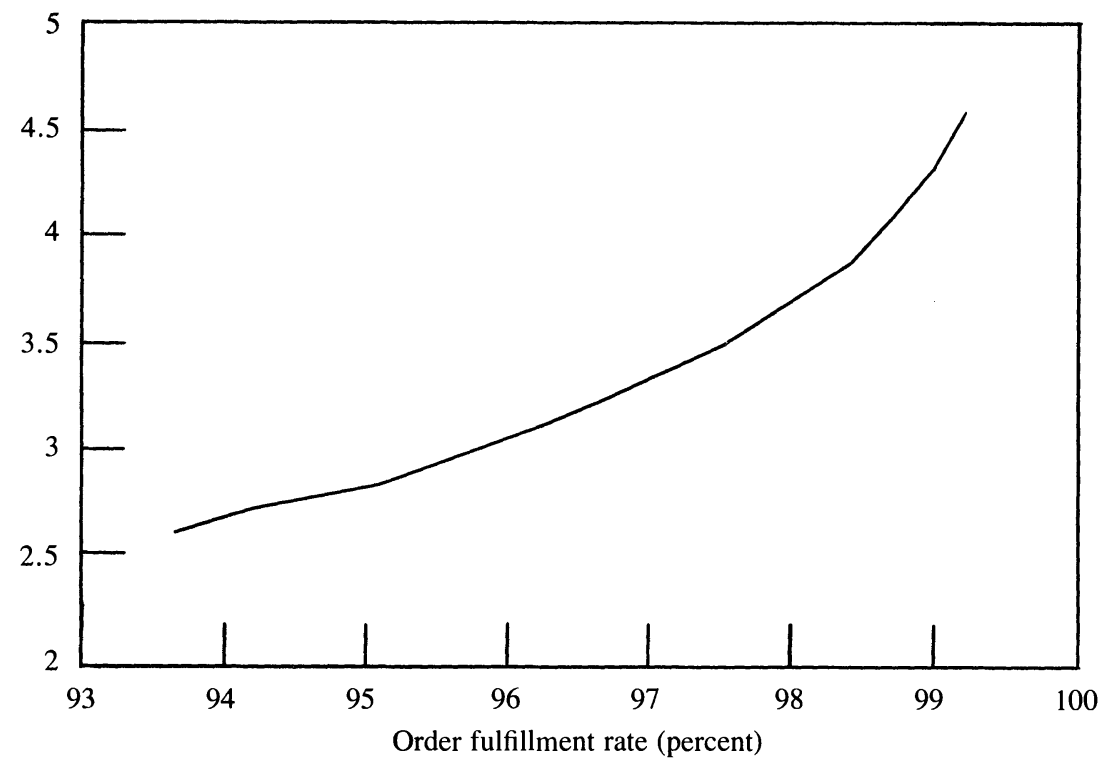

Source: Authors' calculations, assuming that the coefficient of variation equals 0.7 and lead time equals three weeks. ${ }^{a}$ Average inventory divided by average demand.

ORder Fulfillment, Lead Times, and InVEntory ReQuirements. To provide high levels of customer service without holding large inventories, retailers must be able to acquire necessary goods without delay; this in turn requires that manufacturers be able to provide high order fulfillment rates. Figure 2 shows how a manufacturer's finished goods inventory increases as a function of the order fulfillment rate required by the retailer. In the figure we assume that the coefficient of variation of demand and order fulfillment lead time are fixed at 0.7 and three weeks, respectively. This figure is a classic case of the costservice trade-off curve, showing that costs (in this case, the cost of carrying finished goods inventory) increases rapidly as the desired service level rises. ${ }^{25}$

25. Milgrom and Roberts (1988) also analyze how inventory plays a buffering role, the importance of which diminishes as more, reliable information is available. See also Bental and Eden (1993) for a discussion of other motivations for holding inventory. 
To keep their inventories low, lean retailers require short orderfulfillment lead times from manufacturers. Figure 3 shows how a retailer's inventory levels increase as a function of the manufacturers' order fulfillment lead time. In figure $3 \mathrm{a}$, we assume that the coefficient of variation of consumer demand is fixed at 0.7 . The retailer's inventory levels rise as a function of both lead time and desired satisfaction rate; the curve becomes steeper (and hence the incremental inventory needed to cover longer lead times grows more rapidly) as the target satisfaction rate increases. A similar analysis is shown in figure $3 \mathrm{~b}$, which assumes that the consumer satisfaction rate is fixed at 97 percent. Longer lead times and higher demand uncertainty (coefficient of variation) both drive inventory levels higher, with greater incremental inventory needed to cover longer lead times as demand uncertainty grows.

The dynamics driving these results can also be used to demonstrate how manufacturers' internal lead times affect their ability to provide high order fulfillment rates to retailers. For example, if a retailer requires a 97 percent customer satisfaction rate, a manufacturer with a 1 -week lead time requires 2.7 weeks of finished goods inventory, whereas a manufacturer with a 5-week lead time requires approximately 3.75 weeks, or nearly 40 percent more, of finished goods inventory. Thus, internal practices lowering the time from initial orders to product completion can lower the amount of finished goods inventory and therefore exposure to risk.

\section{Predicted Effects of Lean Retailing on Channel Practice and Performance}

Lean-retailing strategies provide a means for retailers to capitalize on information technologies to minimize exposure to demand uncertainty. Adoption of these strategies in turn requires apparel manufacturers to adopt a basic set of technologies to provide the information links required of the strategy and to provide the retailer with a range of services to allow the rapid yet efficient movement of products from distribution centers to retail selling floor. ${ }^{26}$

26. The changes encompassed in lean retailing and the retail-apparel-textile channel can be related to the characteristics of "modern manufacturing" modeled by Milgrom and Roberts $(1988,1990)$. Through the impetus of lean retailers, apparel suppliers are under increasing pressure to fill orders quickly by exploiting new methods of data 


\section{Figure 3. Retailer's Finished Goods Inventory as a Function of Manufacturing} Lead Time

A. ASSUMING A COEFFICIENT OF VARIATION EQUAL TO 0.7

Weeks of inventory ${ }^{a}$

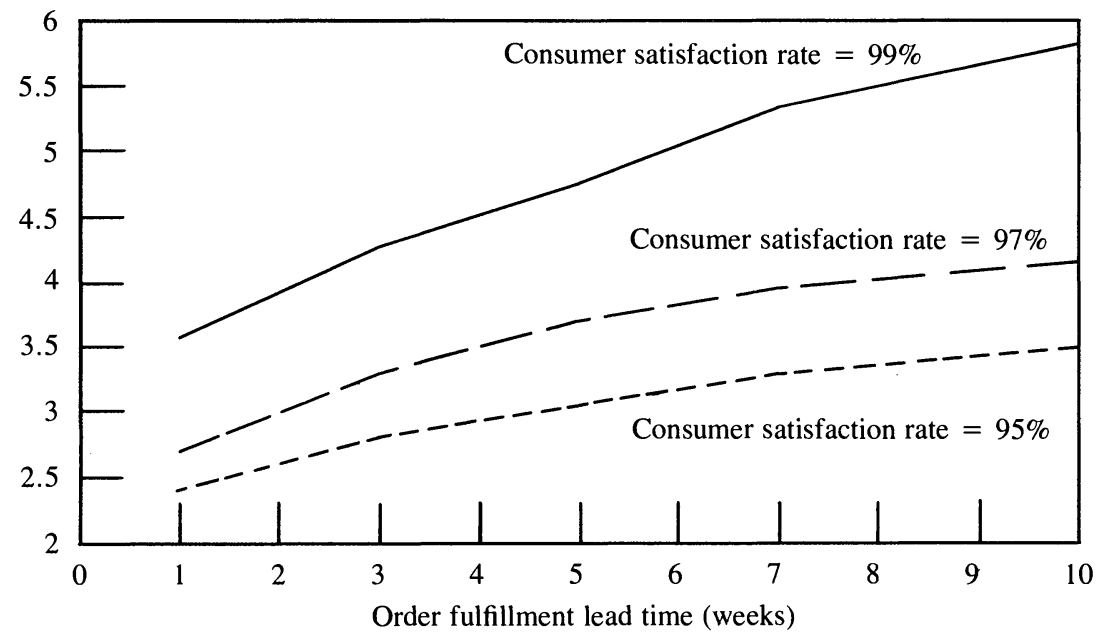

B. ASSUMING A CONSUMER SATISFACTION RATE OF 97 PERCENT

Weeks of inventory ${ }^{a}$

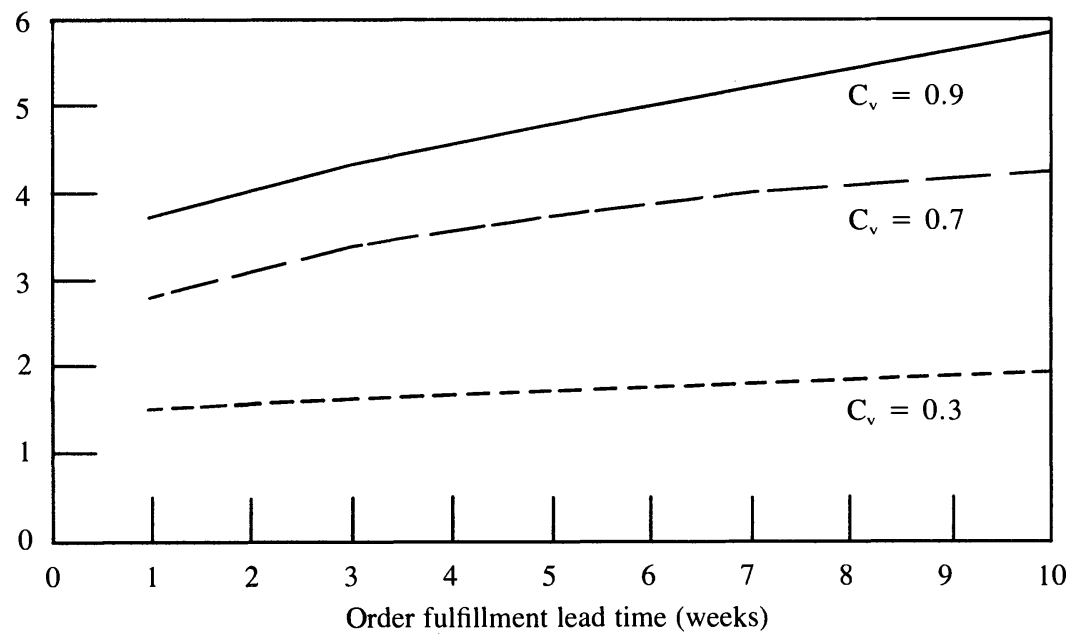


A lean retailer must be able to:

- Track sales on individual styles, colors (fabrics), and sizes on a store-level and real-time basis.

- Replenish products at the store level quickly.

- Hold minimal excess inventories at the store level beyond what is on the sales floor.

- Provide logistical support for the above cluster of store practices (typically through a centralized distribution system).

- Create manufacturer performance standards for replenishable products, specifying standards for order-to-replenishment lead times, shipment accuracy, and delivery information (that is, a detailed description of the contents of the delivery at the SKU level), and setting out penalties for noncompliance. ${ }^{27}$

These changes, in turn, establish performance standards for the business units supplying the lean retailers that are fundamentally different from the traditional standards. Suppliers must be able to:

- Label units, track sales, and respond in real time to product orders at specified style, color, and size levels.

- Exchange (electronically) information concerning current sales and related information with retailers.

- Provide goods to retailer distribution centers in ways that allow the good to be moved efficiently to stores for distribution (for example, boxes marked with computer-scannable symbols concerning contents; shipment of products ready for display in retail stores).

transmission (requiring investment in both software and hardware), improving distribution centers, and adopting more flexible manufacturing technologies. Thus, the "cluster of characteristics . . . often found in manufacturing firms that are technologically advanced" (Milgrom and Robert 1990, p. 526) can be understood as arising from dynamic changes beginning in the product market and rippling backward in the production process.

27. Both of the major retail sponsors of the channel survey (see appendix) and other major retailers interviewed by the authors have extensive written standards. In the case of the department store sponsor, manufacturers who miss replenishment delivery date standards may be penalized by having orders returned. These lean retailers also subject suppliers to fines if shipments do not accurately reflect the retailer order at the SKUlevel (for example, the correct number of shirts at the requested size, color, and style level). 
These practices represent a set of minimum requirements for manufacturers to enter into lean retailing relationships and can therefore be considered an entry cost of working with lean retailers. Diffusion of these minimum standards arises at least in part from lean retailers exerting their market power on their suppliers. ${ }^{28}$

In contrast, the product market does not so clearly drive how an apparel manufacturer chooses to meet lean retailing requirements. As figures 1,2, and 3 illustrated, lean retailing places pressure on apparel suppliers either to raise their inventories of finished goods or to change their internal operating practices substantially. Thus, at one extreme a manufacturer can simply hold inventory for lean retailers with relatively little innovation in its internal practices. At the other end of the spectrum, a manufacturer can alter its internal design, planning, procurement, and manufacturing operations to be able to respond rapidly to demand changes while minimizing the increased exposure to inventory risk arising from lean retailing.

The latter business unit strategy requires development of a second, more advanced, set of internal practices and capabilities, including:

- The ability to forecast and plan future production needs based on sales data provided by the retailer.

- Distribution centers capable of providing the logistical support to efficiently process shipments to multiple retailers (with lean and nonlean operating characteristics).

- Manufacturing practices adapted to producing a variety of styles, sizes, and colors under shorter lead-time requirements.

- Agreement with key suppliers to provide shorter procurement lead times and smaller minimum orders for textiles and other suppliers to accommodate changing demand requirements.

Thus, although we expect lean retailing to lead to wide-scale adoption of the set of minimum requirements, firms supplying lean retailers

28. The history of retailer-manufacturer relations in the industry provides a basis for these observations. Retailer pressure was cited as the motivation for adopting electronic data interchange, bar-coding, scanning, and related practices in a wide range of interviews conducted by the authors with retail, apparel, and textile industry representatives as well as in discussions concerning the adoption of these practices in the food industry. Only in a few cases, typically involving large suppliers with high brand recognition products, has adoption been undertaken through true "partnership" arrangements by both parties. 
can respond in different ways, with one firm meeting retailer requirements by holding buffer stocks, while another may meet the same requirements by investing heavily in production practices and flexible planning. Conceivably, two business units could meet lean-retailing requirements in the short term, yet diverge considerably in terms of their own internal practices and performance. The internal performance of the two firms should differ systematically on the basis of their chosen strategy, however, and internal performance will in turn affect the longterm viability of that strategy.

\section{Working Hypotheses}

The above discussion suggests the following preliminary hypotheses concerning patterns of practice and performance among apparel industry business units:

First, the incidence of "minimum standard" practices and investments by apparel business units should have increased during the 198892 period, paralleling the emergence of lean retailing in the channel. Minimum standard practices can be defined as those baseline practices necessary for an apparel business unit to be able to work with a lean retailer. These capacities consist of providing bar codes at the SKU level, receiving orders and payments electronically, and providing shipping containers with bar-coded information concerning contents.

Second, business units under more intensive lean-retailing pressure should have higher rates of adoption of minimum standard practices. Specifically, more stringent replenishment requirements (daily or weekly delivery, for example) should be associated with higher apparel supplier investments in minimum standard practices (the baseline information practices listed above). These business units should also have higher incidence of clusters of other internal practices (see below) that enable an apparel supplier to improve replenishment speed, procurement lead times, and delivery accuracy.

Third, following Milgrom and Roberts, apparel business units should exhibit distinctive patterns of complementary practices relating to clusters of activities with effects on competitive performance. ${ }^{29}$ Specifi-

29. The theoretical model described by Milgrom and Roberts (1990) concerning the "economics of modern manufacturing", suggests similar changes to those predicted here for the retail-apparel-textile channel. Their modern manufacturing model can be illu- 
cally, these clusters of practices relate to information processing; distribution operations; marking, spreading, and cutting; and apparel assembly.

Fourth, apparel suppliers providing minimum standard practices and those that have invested in additional practice innovations may perform similarly (at least in the short term) along lean-retailing performance outcomes (replenishment speed, garment procurement lead times, and delivery accuracy) but may differ over the long term. Specifically, those business units investing in deeper levels of practice innovation should perform better over the long term, reflecting their reduction in exposure to inventory costs from innovating their own operations.

We use the apparel channel data set in the following section to test these preliminary hypotheses. The diffusion of bar-coding, scanning, software systems, electronic data interchange, and distribution center automation to handle point-of-sale (POS) data goes well beyond the apparel channel, however. As a result, the changes that we document in this paper have potentially wider implications to an economy with greater levels of information integration. This article provides an empirical example of how these changes in manufacturing practice described by popular and academic works can by analyzed in a specific industrial setting.

\section{Analyzing Changes in Retail-Apparel-Textile Channels}

This section reviews changing practice and performance among apparel suppliers in light of the product market changes just described. It begins with a comparison of practice and performance of apparel business units in the sample in 1988 and 1992. Reviewing baseline changes sets the stage for a more intensive analysis of the causes of practice

minated by examining how product market changes (such as lean retailing) lead to changes in apparel business units' information, procurement, manufacturing, and distribution practices. Specifically, while Milgrom and Roberts consider the desire for greater speed in order processing and delivery as a manufacturer decision variable, our analysis of the apparel channel places this manufacturer decision in the context of lean retailing requirements. Similarly, the diffusion of information and distribution center practices along the lines suggested by Milgrom and Roberts should be driven by the degree of rapid-replenishment pressure under which a specific business unit operates. 
change and the relationship between the adoption of certain "clusters" of practice change and business unit performance in the channel.

\section{The Impact of Lean Retailing, 1988-1992}

The changes in the apparel industry induced by lean retailing can be reviewed by examining the increased incidence of minimum standard practices required for supplying retailers, changes in other information relations between retailer and apparel suppliers, shifts in distribution center investments and practices, and the increasing level of services provided to retailers. ${ }^{30}$

Minimum Standard Practices: Information flows between retailers and manufacturers historically have been restricted to product orders, typically transmitted as paper flows. Retailers ordered apparel on the basis of estimates made long before the selling season. Replenishment of these orders during the season was difficult because the retailer did not have the means to collect information on the current status of sales and inventories at a detailed level. For a small group of basic products, such as children's basic underwear, which did not change much from season to season, retailers were able to restock items during the course of the season as stocks were depleted. For most items, however, retailers were forced to live with the costs incurred if they significantly over- or under-estimated consumer demand. Such losses were viewed as unfortunate but unavoidable costs of doing business in a world of volatile product demand.

The diffusion of information technologies among retail and apparel firms has created capabilities to mitigate this problem. Following successful practices in the food industry in the 1970s and 1980s, the apparel industry adopted the same uniform system of bar codes in 1987. Bar codes are distinctive computer-scannable symbols that identify individual products and vendors. Bar codes are scanned at the point of sale, allowing the sale to be recorded and the price to be located in a retail database that lists prices by code. Creation of a standardized system of

30. Comparisons are made on the basis of unweighted means for specific business unit practices in 1988 and 1992. Comparisons of practices in 1988 and 1992 weighting business unit operations by sales volume result in similar but even larger estimated changes in business unit practice than those presented in this section. This arises because the large apparel suppliers in the sample have higher rates of adoption of innovative practices. 
classification of products (Uniform Product Code, or UPC, symbols) supported the adoption of these technologies, providing a "common currency" for information exchange between retailer and manufacturers (and potentially to suppliers further back in the channel).

To work with lean retailers, suppliers must invest in these practices. First, a supplier must be capable of labeling its entire product line with industry-standard bar codes. Second, it must invest in the capability to receive and process large quantities of data. The most rapid and accurate method of data transmittal is through electronic data interchange which allows a manufacturer or retailer to send information electronically from its own computer directly to the information processing system of its supply channel partner.

The first section of table 3 presents comparisons of the prevalence of these two minimum standards as well as of model stock programs governed by retailers (which require a similar baseline combination of practices) in 1988 and 1992. ${ }^{31}$ As predicted, the increases in the adoption of these core information practices by business units between 1988 and 1992 were dramatic and statistically significant: the percent of product volume labeled with UPC bar codes at the SKU level increased from 22 percent in 1988 to 60 percent in 1992 (the prevalence of manufacturer products with product codes registered in the UPC catalog also increased appreciably), and purchase orders received through EDI rose from 4.5 percent to 31.6 percent of all volume shipped.

The incidence of model stock programs governed by retailers also increased significantly, more than doubling from 7 percent in 1988 to 16 percent in 1992 of total volume shipped among business units. A smaller, but again statistically significant increase, occurred in the incidence of model stock programs governed by manufacturers, perhaps reflecting the dominance of retailers in instigating new channel relationships.

The overall increase in the prevalence of minimum standards is further illustrated by examining the number of business units in the sample that were both using UPC bar codes and EDI. In 1988, this group accounted for twenty-eight business units ( 23.7 percent) in the sample.

31. In a model stock program, a retailer and a supplier agree on target inventory levels for each product at each retail site. The supplier uses information-order or sales data-transmitted from the retailer to the supplier to replenish items as they are sold, thus maintaining the target inventory distribution. 
By 1992, seventy-six (64.4 percent) were shipping some percentage of their volume using bar codes and receiving orders through EDI.

Advanced Information Practices. Business units investing only in minimum standard practices do not necessarily receive from retailers detailed information-other than electronically transmitted ordersconcerning patterns of demand for products. Apparel suppliers that do not have the capability to receive such information from their retailers are at a disadvantage in their ability to plan effectively. Sterman modeled the dynamics of a four-level supply channel in which information flow is limited to orders to show how firms in the channel react to having only order information available when making planning decisions. ${ }^{32}$ Despite the directive to minimize channel costs, company managers in Sterman's experiments tended to make decisions that they believed would minimize their own costs, often at the expense of their channel partners. In addition, Sterman notes that several patterns emerged in channel order patterns: oscillation of the order pattern over time, amplification of the oscillation as the orders moved back in the supply chain (that is, from the retailer to the factory), and phase lagthe oscillations at the back end of the supply channel lag those in the front of the channel. These patterns together are often referred to as the "bullwhip effect,", on which early research was conducted by several macroeconomists. ${ }^{33}$

The provision of POS data would negate much of the distortion brought about by the forces Sterman identifies. Lee, Padmanabhan, and Whang show that to manage the bullwhip effect, it is necessary to share sell-through and inventory status data throughout the channel, coordinate ordering processes across retailers, and simplify the pricing and promotional activities of the manufacturer. ${ }^{34}$ In addition, shared information reduces a channel member's ability to "game" the system by using its ordering process to send false signals through the channel.

The sample data shows that the POS data apparel manufacturers receive, both from individual stores and in the aggregate, has increased. In the former case, the provision of POS data tripled between 1988 and 1992 , to 15 percent of shipments, while aggregated data more than doubled. Nonetheless, despite the high prevalence of information links

32. Sterman (1989).

33. See, for example, Holt and others (1960), Blinder (1982), and Blanchard (1983).

34. Lee, Padmanabhan, and Whang (1994). 


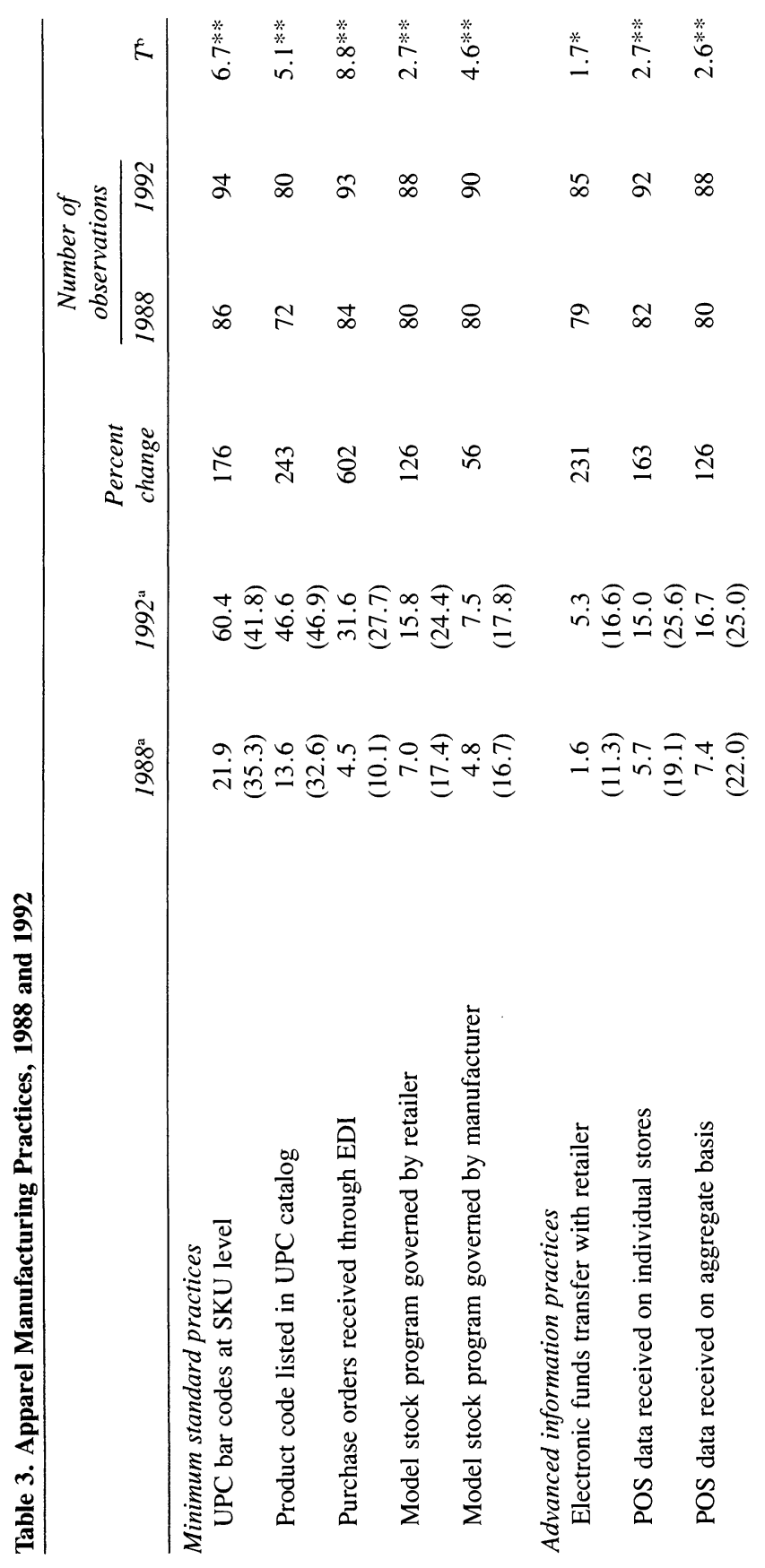




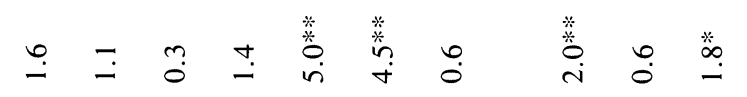

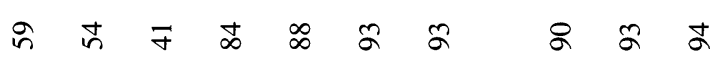

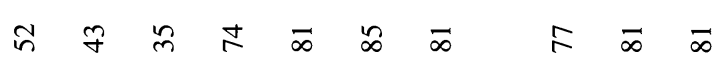

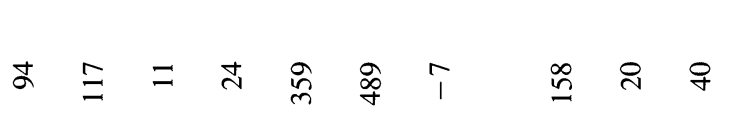

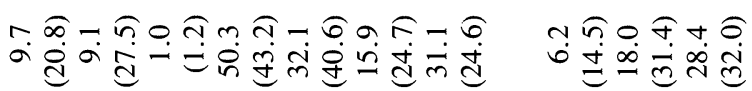

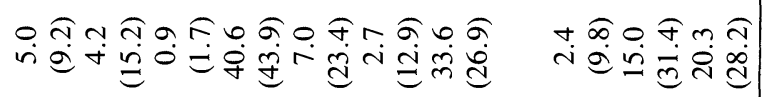

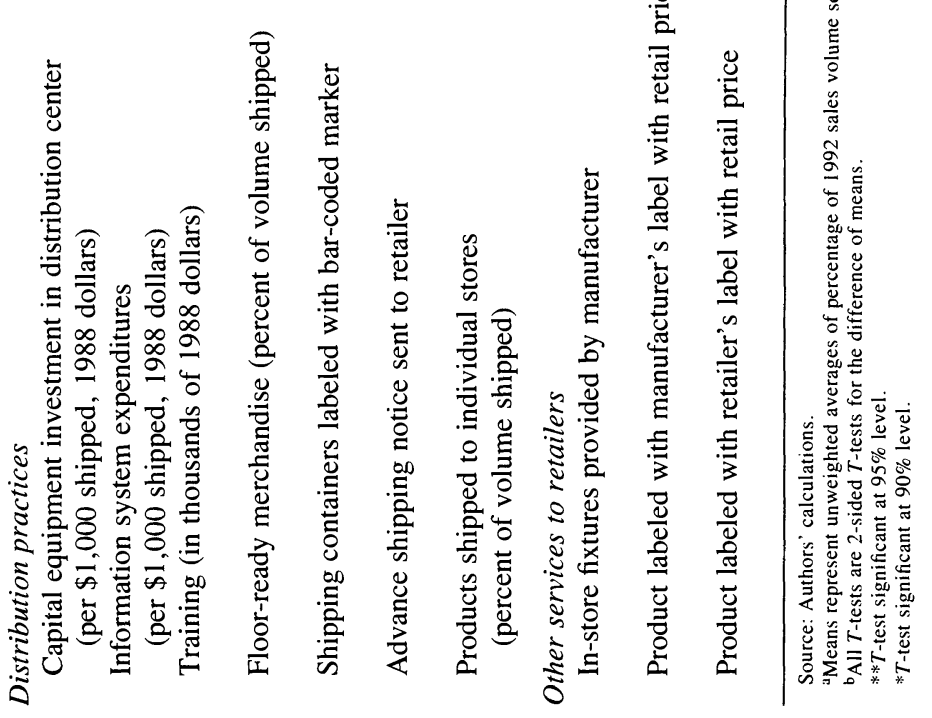


between retailers and apparel suppliers in 1992, 44 percent of orders transmitted were not accompanied by POS data or sales forecasts. By not sharing POS information with suppliers, retailers are limiting the ability of apparel manufacturers to forecast future demand and plan production accordingly.

Distribution Practices. Distribution practices are also changing. Historically, products were shipped from the plant to a manufacturer's warehouse; later, when retail orders were received, the products would be transported to the retailer's warehouses. The time-sensitive nature of lean retailing requires that minimal time elapse between the placement and the delivery of an order. In the most sophisticated systems, warehouses have been replaced by highly automated distribution centers at both the manufacturer and retailer levels. These centers locate and label finished products and direct them to appropriate carriers for delivery to a retailer distribution center. The retail distribution centers, in turn, scan information from computer-generated labels on shipping containers for rapid cross-docking and shipment to the appropriate store. ${ }^{35}$

Manufacturer practices that provide the capabilities for such sophisticated distribution of products have increased markedly. Overall average annual capital expenditures in the distribution center increased from $\$ 5.00$ per $\$ 1,000$ shipped in the $1987-89$ period to $\$ 9.70$ per $\$ 1,000$ shipped in the 1990-92 period, as measured in 1988 dollars. Increases in investments in information systems specifically to support distribution were comparable, rising from $\$ 4.20$ to $\$ 9.10$ per $\$ 1,000$ shipped in 1992.

Apparel suppliers can set up their distribution operations to augment information links between retailers and manufacturers by applying labels and establishing systems to inform retailers regarding incoming shipments. Table 3 reveals that several such practices increased between 1988 and 1992. These include:

- Delivery of floor-ready merchandise to retailers, which rose from 40.6 percent to 50.3 percent;

- Marking the outside of each shipping container with a bar code so

35. Table 3 shows a decrease (from 33.6 percent to 31.1 percent) in shipments by manufacturers directly to stores rather than to a retailer's centralized distribution operations; direct shipment from the manufacturer to stores has decreased as retailers' internal distribution capabilities have developed. 
that the retailer does not have to open the container to find out what is in it; this practice increased from 7 percent to 32.1 percent; and

- Providing advanced shipping notification to retailers electronically, which increased from 2.7 percent to 15.9 percent.

Other Services to Retailers. The incidence of several other services that manufacturers provide to retailers is also increasing. The bottom portion of table 3 shows a moderate increase in manufacturers picking up part of the work usually done by retailers, such as labeling products with the retailer's price in advance. There was a greater percentage increase, however, in the number of suppliers that provide retailers with fixtures for product presentation. A small portion of business units (primarily larger firms with established product labels) in the sample charge retailers for these services, a practice that seems consistent with market power elements underlying the larger trend towards retailer-driven channel innovation.

Thus, by 1992 the basic standards necessary for greater informationintegration in the channel had been established. Although the survey results indicate that certain types of minimum standard practices have become prevalent, considerable variation across practices and among business units remains.

\section{Linking Pressure to Practice}

Channel integration in the apparel industry seems to have affected the nature of information transfer between retailers and suppliers, order fulfillment processes, distribution operations, and related services. But the manufacturing process extends further back to the design, cutting, and sewing rooms and even further back to supply relations between apparel producers and textile suppliers. The degree to which lean retailing has affected all of these aspects of the industry bears further examination.

One method of investigating the depth to which product market changes have affected manufacturer practice is to examine those practices in business units facing different degrees of rapid-replenishment pressure. We argued above that some level of heterogeneity in production system response is likely. One would nonetheless expect to find a greater degree of change in information systems, procurement, distri- 
bution, and production practices for business units providing a large percentage of their volumes on a frequent replenishment basis than for units providing little or nothing on that basis.

Tables 4 and 5 show the results of analysis of this question. Table 4 presents comparisons of business units in the sample broken into two categories: those providing at least 15 percent of their volume to retailers on a daily or weekly basis were classified as operating under "high" levels of channel pressure; those providing less than 15 percent on this basis were classified as being under "low" levels of channel pressure. ${ }^{36}$ (The 15 percent figure was chosen based on a cluster analysis of the data.)

Other factors can potentially confound such comparisons, however. First, the product mix of a given business unit is correlated with manufacturing choices and with the degree to which its goods are subject to replenishment requirements. Thus, the type of products provided by business units (as classified by fashion content) must be explicitly controlled. Second, the degree to which apparel suppliers invest in "innovative" practices may be a function of firm size as well as the degree of replenishment pressure. Both factors must therefore be controlled explicitly in order to gauge the independent effect of replenishment pressure on practice.

Table 5 presents the results of a set of regressions modeling the determinants of various business unit practices. Specifically, the model measures replenishment pressure as a continuous variable based on the reported percentage of products retailers demand on a daily or weekly basis. To control for the confounding impacts of fashion-content and firm size, the model includes a variable measuring the percentage of the business unit's shipments that can be classified as "basic" or "fashion-basic"' and a variable measuring the total dollar shipments of the business unit in 1992. ${ }^{37}$ The significance of the coefficients for size

36. We use frequency of daily or weekly replenishment as a proxy for pressure for frequent replenishment because it is a direct expression of a core performance requirement for lean retail suppliers; most apparel firms prefer less frequent delivery schedules, all else equal.

37. The use of other variables to capture fashion content related to the number and turnover of SKUs results in similar estimated impacts in most cases. Complete regression results are available from the authors. 


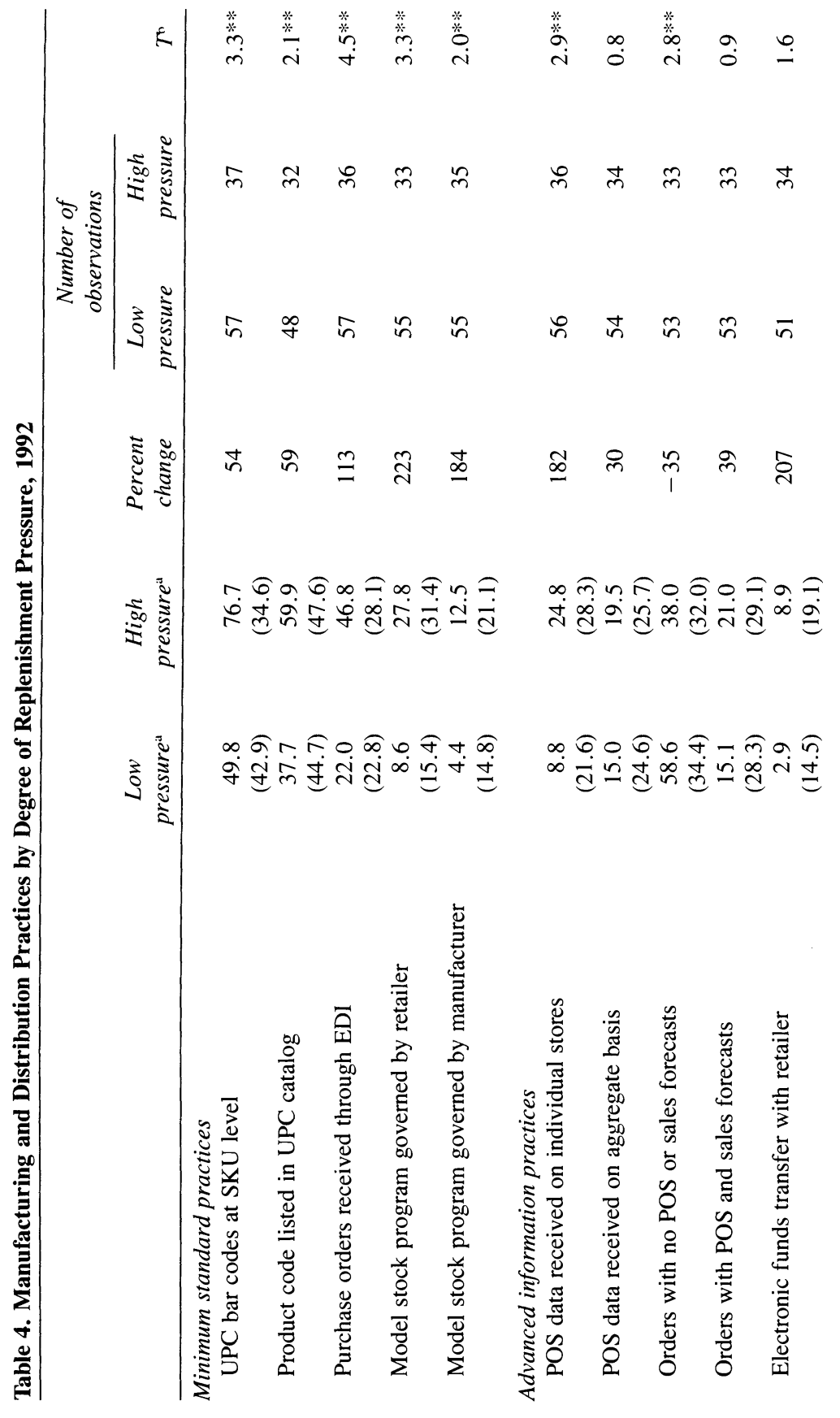




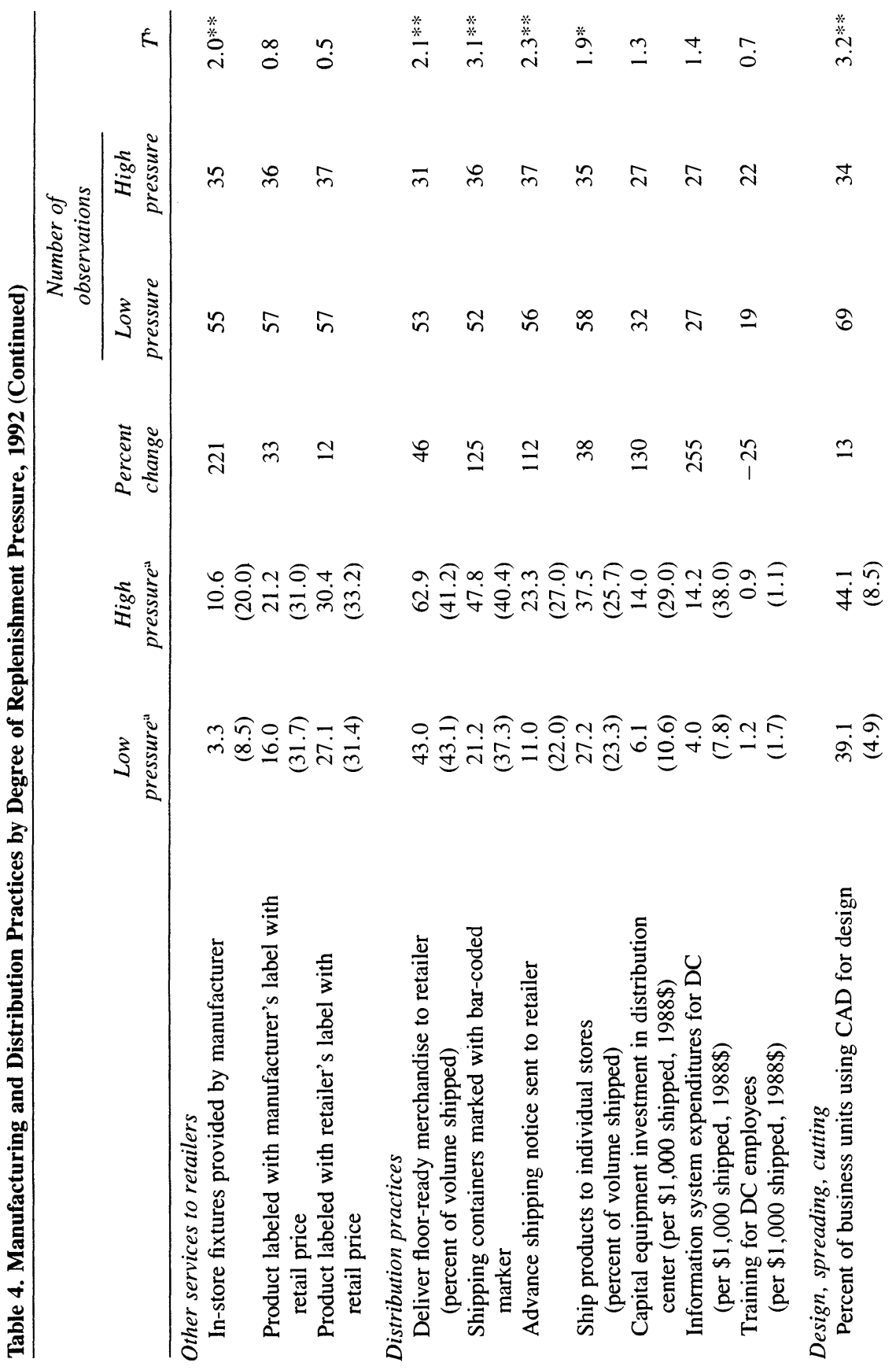




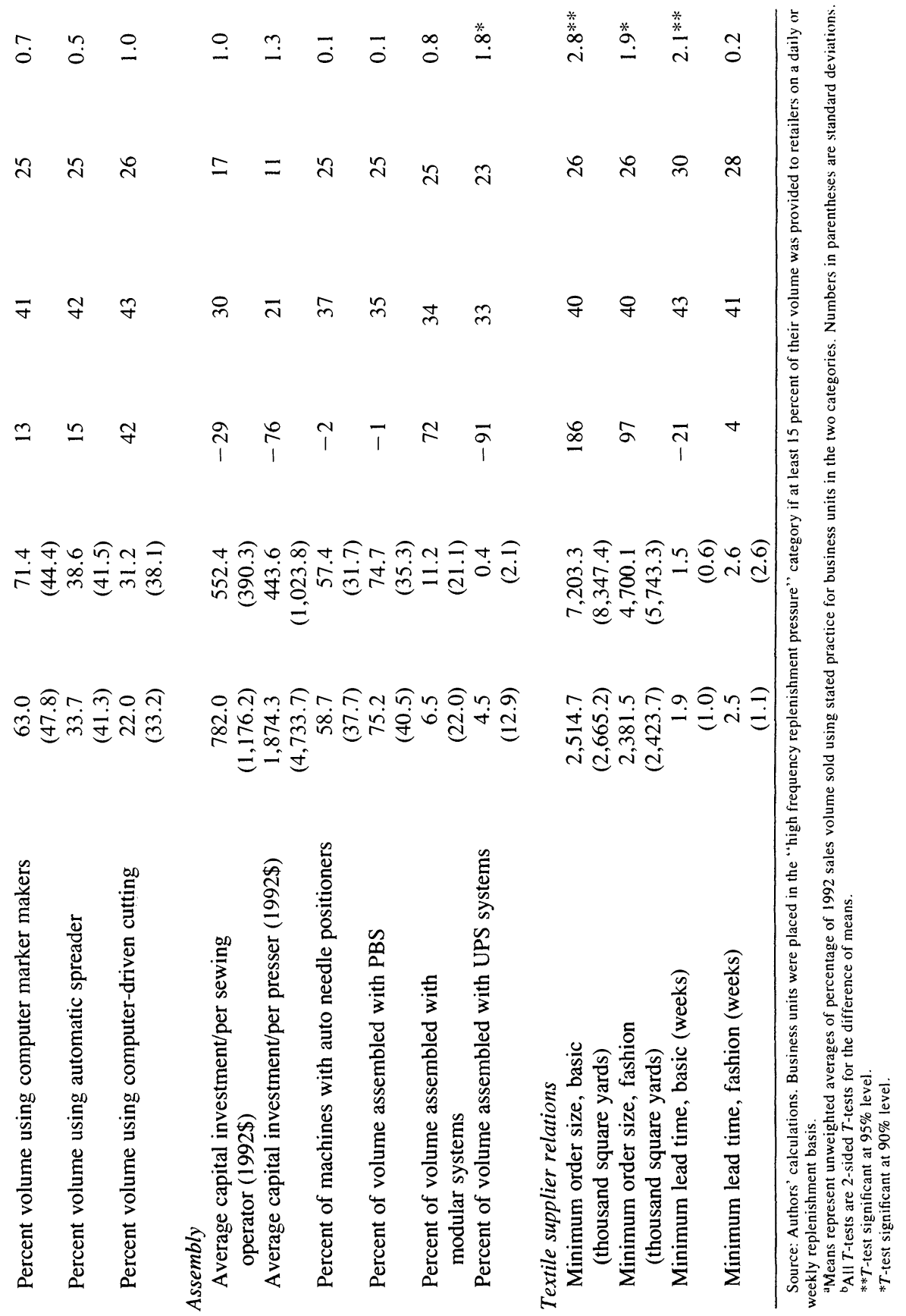




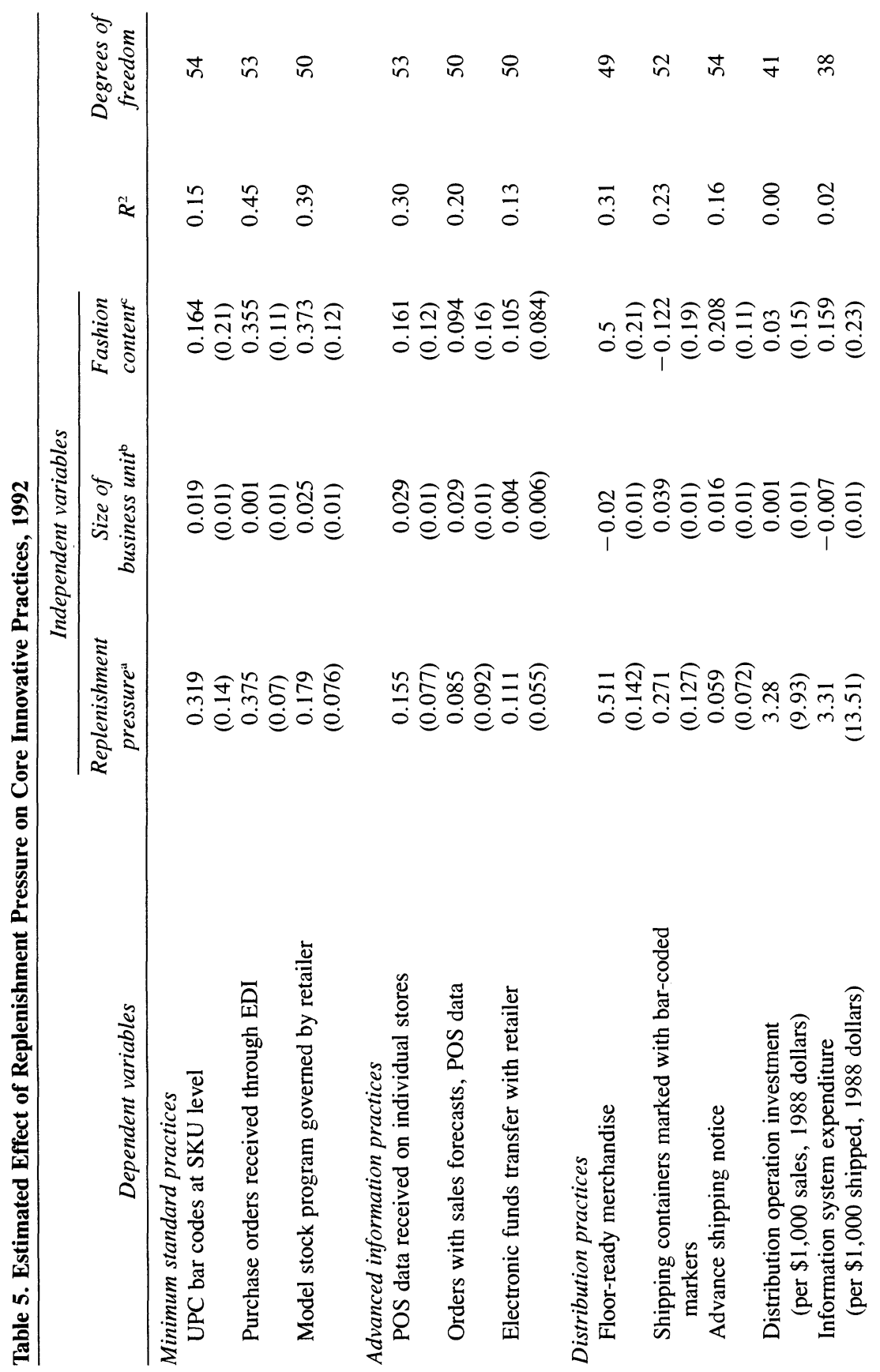




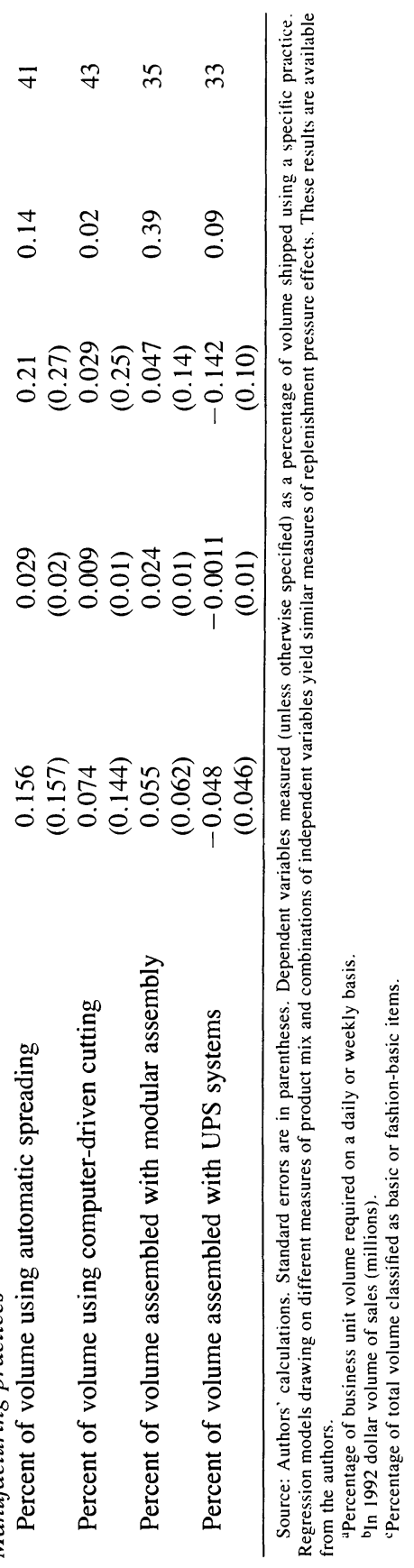


and fashion content in the regressions confirms our hypothesis that these are important control variables. ${ }^{38}$

Minimum Standard Practices. The upper portion of table 4 compares the prevalence of the minimum standard practices required for lean retailing between business units facing low degrees of replenishment pressure in 1992 and those facing high degrees of pressure. The results in each case are striking and consistent with the hypothesized relationship: the more the pressure to provide frequent replenishment services, the greater the degree to which business units relied on these information links in their relations with retailers. For example, more than 40 percent of volume shipped to retailers among the "high" pressure group is shipped under some type of model stock program.

The reported coefficients for the minimum standard practices confirm that the fashion content or size of business units in the high pressure group cannot explain these results (see table 5). The estimated coefficients on the effect of changes in replenishment pressure are positive, large, and statistically significant for UPC bar-coding, for electronically transmitted purchase orders, and for model stock programs governed by retailers.

Advanced Information Practices. The degree to which retailers share information with their suppliers is positively related to the degree of replenishment pressure. For example, nearly 25 percent of total volume shipped by business units under high replenishment pressure are accompanied by store-level POS data, compared with only 9 percent for those under low pressure (see table 4). Similarly, 60 percent of volume shipped by those under low replenishment pressure are not accompanied by any sort of information on sales or forecasts. This positive relationship between provision of POS data and replenishment pressure remains even after controlling for size and fashion content (see table 5). Nonetheless, POS data or forecasts are not provided for 38 percent of the volume shipped by the high replenishment group, indi-

38. The practice variables used in the analysis are measured as the percentage of volume shipped by the business unit using the stated practice. They are therefore bounded dependent variables ranging from zero to 100 percent. If observations are clumped at either extreme, OLS regression would result in biased estimates of the pressure-practice relation. To deal with this potential problem, logit regressions were run for those cases where the distribution of dependent variables exhibited clumping at zero or 100 percent. The sign and significance of the resulting estimates were similar to the OLS coefficients for the replenishment pressure variable reported in table 5. 
cating significant barriers to information sharing among business units in the channel as noted above. ${ }^{39}$

Distribution Practices. As argued above, lean retailing requires that apparel firms have distribution systems capable of identifying, labeling, and moving products from the manufacturer's distribution center to the retailer's distribution center in minimal time. Thus, one would expect to find significant differences in distribution center practices as well as in investments in capital equipment, information systems, and training among firms facing low and high rapid-replenishment pressure.

Table 4 provides evidence that such differences do exist. Specifically, those units facing high replenishment pressure are more likely than those facing lower pressure to send retailers advanced shipping notices, attach bar-coded markers to shipping containers, and ship floorready merchandise. The regression results confirm these results as large and statistically significant except in the case of advanced shipping notices.

A comparison of capital expenditures for distribution center operations adjusted for sales volume demonstrates that business units facing high pressure have responded by investing more heavily in their distribution centers. Specifically, they invest more than twice the amount per $\$ 1,000$ of sales than those facing low pressure. Similarly, information system investments are almost double for the high pressure group. In contrast to other aspects of distribution center investments, however, these results diminish when controls for size and fashion content are included in regressions. ${ }^{40}$

Design, Cutting, and Sewing Room Practices. Most studies of the apparel industry in both the academic and trade literature focus on developments in the cutting and sewing rooms. A channel-based perspective embeds these activities in the larger context of manufacturing decisionmaking that also includes the information practices described above and the distribution and supply relationships discussed below.

39. Case studies conducted by the authors indicate that retailer reluctance to provide such information to suppliers represents a major obstacle to transfer of detailed POS data.

40. Note, however, that the coefficients of these variables are relatively large and positive. The large standard errors of the estimates reflecting the high level of dispersion in capital investments per sales dollar leads to low statistical significance. 
Focusing solely on design, cutting, and sewing operations would provide an incomplete picture of larger developments.

Cutting room practices can affect dramatically the responsiveness of an apparel manufacturer in several respects. First, the time required to set up to cut new styles and sizes becomes more important as business units offer more product variety and hence less volume per style. Second, particularly in more fashion-oriented segments of the channel, the ability to make an efficient pattern layout, or "'marker," quickly may confer competitive advantage on a manufacturer. These benefits contrast with the historical focus of technological innovation in the cutting room: reducing the amount of wasted material arising from cutting operations and maximizing equipment productivity.

The survey results indicate the presence of differences in the use of design and cutting technologies within the industry. For example, 39 percent of business units facing low rapid-replenishment pressure use computer-aided design (CAD) for design, compared with 44 percent of those facing high pressure. The use of computerized marker systems is widespread; these systems allow cutting room operators to configure pattern pieces on computer screens rather than through a manual process involving laying paper pieces on rolled-out fabric. Business units facing low replenishment pressure drew on these computerized systems for an average of 63 percent of business unit dollar volumes, compared with 71 percent for those facing high pressure. In addition, units facing high replenishment pressure rely more heavily on computer-assisted die cutting or laser cutting than those under lower pressure. The modest impacts of replenishment pressure on cutting room practices disappear, however, when size and fashion are included in regression models (see table 5).

The sewing room similarly shows relatively modest effects of replenishment pressure. Capital investment per worker remains low in sewing and pressing operations and was actually lower among those firms facing high replenishment pressure. One interpretation of this finding is that firms facing the highest pressure for rapid replenishment were investing their resources in distribution center operations, focusing on those activities that directly affect relations with retailers rather than on their own internal operations.

The established system of assembly in the apparel industry is the progressive bundle system (PBS). A PBS entails breaking garment 
assembly production into a long series of simple work steps, each completed by a different worker. A major by-product of the bundle system is that it relies on buffers between assembly operations to balance the line and maximize worker productivity. Standard practice is to place an average of one day of inventory between each operation, resulting in large work-in-process inventories ${ }^{41}$ In addition, manufacturing throughput times are long. For example, approximately forty days of work-in-process inventory would be created during the manufacture of a bundle of men's pants requiring forty operations, and for a given pair of pants, at least forty days would be required to transform cut pieces into final product.

There are at least two alternatives to PBSs. Modular or team production systems group together multiple sewing tasks, allowing a group of sewing operators to assemble an entire garment (possibly relying on a PBS for garment subcomponents). Unit Production Systems (UPSs) seek to reduce the size of the buffers built into PBSs by automating the flow of work between stations. The major advantage of both alternative systems is that they reduce substantially the amount of time a given apparel product takes to move through the assembly process. The more rapidly a manufacturer can move a product through the assembly process, the lower the work-in-process inventories.

The design intent of a PBS is to minimize the direct labor content per unit produced; this objective is achieved at the expense of large work-in-progress inventories. Thus, the comparative benefits of this system fall as the benefits of time and flexibility grow relative to the direct cost advantages of minimizing labor content. For the business units in the sample, approximately 13.1 working days were needed for a single apparel item to move from cut pieces to a completed garment ready for packaging in a PBS, compared with 2.6 working days in a modular system and 4.4 days in a UPS.

Despite these advantages, survey results indicate that the vast majority of sewing rooms continue to rely on PBSs rather than alternative systems, regardless of the degree of replenishment pressure they face. Progressive bundle production systems are equally common in both groups, representing about 75 percent of the dollar volume manufac-

41. The target buffers between different steps obviously vary within an assembly line in order to achieve overall line balance. 
tured in apparel plants (see table 4). Modular assembly systems are almost twice as common among business units facing high levels of replenishment pressure than among units facing low pressure. This is not surprising, because the shorter lead times associated with modular systems would mitigate the increase in finished goods inventories associated with faster and more frequent replenishment activity. This association is not statistically discernible once the effects of fashion content and business unit size are accounted for in the model (see table 5).

Supply Relationships. Just as manufacturers must change their operations to support the greater level of replenishment activity in the channel, suppliers to apparel manufacturers ultimately must become more responsive in providing textile products and other key inputs, such as zippers, buttons, and thread. Historically, these supply relationships have been arms-length market relations having a central focus on cost. The nature of textile production economies has motivated production strategies based on long runs of a given product, which in turn have led to large minimum order quantities and long lead times for fulfilling textile orders.

A comparison of two measures of textile supplier performance between 1988 and 1992 indicates little change in the performance of this stage in the channel. As reported by business units in our sample, minimum order sizes for textile fabrics remained virtually unchanged for basic fabrics - those with relatively high and stable demand-and declined only slightly for fashion fabrics - those with a shorter life cycles and less easily predicted demand-despite the larger shifts documented in the retail and manufacturing segments of the channel. Similarly, minimum textile order fulfillment lead times decreased only marginally.

The data in fact show that minimum fabric order quantities were higher for those units facing high replenishment pressure; that may be because the highest replenishment pressure takes place in more basic apparel product categories; thus "high pressure" is acting as a proxy for "more basic" products, which tend to be sold in larger quantities.

Similarly, the minimum lead times offered by textile suppliers are about the same whether the business unit is under low or high replenishment pressure, although lead times for basic fabrics are about 20 percent lower for business units under high replenishment pressure. As expected, lead times for fashion fabrics are longer than for basic fabrics; 
despite the potential premium for shorter fabric lead times, apparel firms must wait more than two months from order to receipt of fashion fabrics. These results are confirmed by regression modeling. The lack of change in relations between apparel and textile manufacturers represents the greatest barrier to reducing the overall amount of channel inventories. ${ }^{42}$ As apparel firms increase their investments in faster, more flexible operations further back in their internal operations (such as distribution, cutting, and assembly operations), the need for adaptation by the textile firms that supply those operations will undoubtedly rise. ${ }^{43}$

\section{Linking Practice to Performance}

Clearly, innovations in the apparel channel are "rippling backward" slowly, with retailers now acting as the primary drivers of change. Retailers require apparel suppliers to invest in a set of basic information technologies and to meet increasingly stringent retail service requirements for short lead times and high order fill rates. At this point, as long as suppliers satisfy these requirements, most retailers are relatively unconcerned about how those suppliers develop the internal capabilities to do so. Thus we see greater adoption of practices close to the retailermanufacturer interface than in apparel firms' manufacturing practices. The incentive to invest diminishes considerably as one moves back further in the channel.

The findings reported in the previous section indicate that business units in the apparel channel currently exhibit heterogeneous manufacturing practices, even within a given segment of the industry. Part of this heterogeneity arises because many of the changes documented here are in transitional stages of development. In the short term, a spectrum of manufacturer practices that meet immediate retail requirements (including holding more finished goods inventory) are sustainable. As lean

42. Several textile firms, however, are using short lead times and small minimum order sizes as the basis of competitive advantage. The relatively small size of individual apparel enterprises compared with other major purchasers of textile products such as the automobile industry may help explain the slow pace of change in textile supplier practices to date.

43. These developments potentially provide empirical cases to examine the incentives for vertical integration or alternative forms of integration as suggested by Williamson (1979), Grossman and Hart (1986), and Johnston and Lawrence (1988). 
retailing practices continue to diffuse, and as the comparative advantages of certain clusters of these practices emerge, the degree of heterogeneity in manufacturing practices should decrease, much as the system being replaced by lean retailing and information integration emerged in the first decades of the twentieth century.

This section provides a preliminary investigation into how these practices affect performance. To conduct this investigation, we have grouped the business units in the sample according to the degree to which they have adopted certain "clusters" of innovative practices. Using these groupings, we examine whether there are systematic differences in performance across these groupings, holding other potentially confounding factors constant.

We have used the general groupings of practices presented in tables 4 and 5 to classify business units into larger practice clusters based on the "depth" of their investments in innovative practices. At one end of the spectrum are apparel suppliers that have undertaken no systematic changes in any phase of their manufacturing operations. At the other end are business units that have made substantial investments in information links with retailers; that receive and use POS data in forecasting and production planning; that employ sophisticated techniques in distribution operations; and that have altered methods of designing, cutting, and assembling products to reduce cycle and lead times. Between these two extremes are business units that have established the information links with retailers but made limited investments in their internal operations.

To compare our sample in this manner, forty different practices (most of which are examined in the previous section) were classified according to how deeply they penetrated an apparel manufacturer's internal practices. These practices were also correlated with one another to find evidence of "clustering"' of complementary practices within and across these practice groupings. ${ }^{44}$ This analysis reveals the presence of one set of practices that tends to be associated with several others within a group of possible practices (for example, what practices within distri-

44. The correlation analysis is available from the authors. The method described here provides a way to find the relationship between a large number of interrelated practice variables and performance measures. Future research will test the robustness of the findings presented here by drawing on principal components analysis to construct a set of linear combinations of the original variables; see Hotelling (1933). 
bution operations tend to be seen together). Case-based research on business unit practices ranging from industry "leaders" to those that have not altered practices in recent years provided us with additional evidence on how business units in the sample differ according to their use of clusters of innovative practices.

Based on this procedure, business units in the sample can be classified into three groups according to their investment in the following practice clusters: ${ }^{45}$

Model 1. This group is composed of business units that have invested in minimum standards for lean retailing but have not undertaken any other clusters of innovations in information systems, distribution, marker-making, cutting, or sewing operations. Specifically, Model 1 units provide UPC bar codes, receive orders through EDI links, and may have model stock programs governed by retailers, but they have not made other systematic investments.

Model 2. The second group of apparel business units have invested in these minimum standards and also have access to more detailed information on sales patterns, information that allows them to enhance their ability to forecast orders. Specifically, Model 2 units meet Model 1 requirements and receive from retailers both retail forecasts and storelevel retail sales data, but they have not invested in any further modifications in their manufacturing operations.

Model 3. These business units have invested in the above practices and have undertaken at least some modifications to their manufacturing and distribution center practices. Specifically, they have adopted at least one of the following practices:

- Attach bar codes on shipping containers

- Provide retail customers with floor-ready merchandise

- Invest in distribution operations above the mean for the sample (measured in dollars per $\$ 1,000$ shipped)

- Use CAD, automated marker-making, or automated cutting

- Introduced some modular assembly systems in their sewing rooms

Each of these groups are compared with a control group of "noninnovating" business units that do not satisfy the conditions for any of these

45. The categories are mutually exclusive and (with the group of business units that have not invested in any clustering of practices) collectively exhaustive. 
distinct clusters of practices. ${ }^{46}$ The bottom rows of table 6 provide information on characteristics of business units in each of the four groups.

Relating Practices to Performance: The channel perspective described throughout this article suggests two types of performance measures. The first set of measures is closely related to requirements for business units operating in a channel under lean-retailing principles: high levels of order completeness, short lead times to procure materials and manufacturer products, and short time requirements for replenishment. These capabilities can therefore be considered measures of channel performance, because they measure the ability of the unit to supply retailers along key dimensions.

The second set of outcomes are more directly related to the performance of the business unit itself. These include standard measures of financial performance (gross margins and operating profits), sales growth, and the number of times the inventory of finished goods turns over each year.

Table 6 presents the mean values for these two categories of performance outcomes across the three innovation models and the control group. The first three measures of channel performance demonstrate striking effects of differing practice clusters. Estimates of order fulfillment time, the measure of the average amount of time it takes for suppliers to respond to replenishment orders, show that model 1 business units require 0.7 weeks less than control group units. More dramatically, Model 3 units, the most advanced in the sample, fulfill replenishment orders twice as fast as the control group and 40 percent faster than the the Model 1 units.

The clusters of practices also affect procurement lead times-the total time required in the apparel production process from the time fabrics are ordered to the time finished products are ready for shipment by the business unit. These lead times are measured in elapsed calendar days for two scenarios for each business unit: that unit's "standard," or average, lead time and its "shortest," or best, lead time for products manufactured domestically. Estimated mean standard procurement lead

46. This includes business units that have made no investments in practices and those that have invested in several practices not conforming to the clusters used in the model (for example, business units that undertake modular production but do not receive orders through EDI). 
Table 6. Business Unit Practice Clusters and Performance, 1992

\begin{tabular}{lcccc}
\hline & No & & & \\
& innovation & Model 1 & Model 2 & Model 3 \\
\hline Channel performance & & & & \\
Order fulfillment time for & 2.90 & 2.23 & 1.92 & 1.32 \\
$\quad$ replenishment products (weeks) & $(2.20)$ & $(1.94)$ & $(0.94)$ & $(0.86)$ \\
Procurement lead time-standard, & 128.90 & 73.86 & 56.25 & 79.20 \\
$\quad$ domestic source (days) & $(95.10)$ & $(45.10)$ & $(2.48)$ & $(56.40)$ \\
Procurement lead time-shortest, & 71.20 & 41.08 & 19.38 & 47.80 \\
domestic source (days) & $(53.30)$ & $(32.84)$ & $(6.54)$ & $(41.42)$ \\
Percentage of goods delivered on time & 91.20 & 90.29 & 91.33 & 88.54 \\
& $(9.10)$ & $(9.55)$ & $(10.02)$ & $(7.78)$ \\
Percentage of orders delivered & 86.70 & 86.41 & 97.60 & 86.50 \\
complete & $(16.30)$ & $(16.11)$ & $(2.51)$ & $(8.35)$ \\
Business unit performance & & & & \\
Gross margins as percent of sales & 27.70 & 25.98 & 34.80 & 25.75 \\
& $(9.40)$ & $(10.61)$ & $(3.30)$ & $(17.20)$ \\
Operating profits as percent of sales & 5.00 & 9.47 & 9.10 & 10.54 \\
& $(4.20)$ & $(8.61)$ & $(11.46)$ & $(4.00)$ \\
Sales growth between 1988 and 1992 & 36.00 & 26.63 & 61.68 & 38.11 \\
$\quad$ in 1988 dollars) & $(84.90)$ & $(60.58)$ & $(1.78)$ & $(88.87)$ \\
Finished goods inventory turns per year & 7.34 & 6.68 & 5.33 & 5.35 \\
& $(9.61)$ & $(6.51)$ & $(2.52)$ & $(2.15)$ \\
Business unit characteristics & & & & \\
Number of business units in category & 42 & 54 & 4 & 18 \\
Volume of sales (millions of dollars) & 55.00 & 139.65 & 94.00 & 339.82 \\
& $(54.80)$ & $(289.35)$ & $(84.77)$ & $(618.43)$ \\
Percent of sales in basic and & 49.50 & 74.28 & 68.00 & 78.51 \\
fashion-basic categories & $(37.50)$ & $(27.33)$ & $(18.06)$ & $(25.06)$ \\
\hline
\end{tabular}

Source: Authors' calculations. Means are based on unweighted averages for practice cluster category. See text for definitions of business unit practice clusters.

times are far lower for innovative business units than for the control group of noninnovators. The shortest lead times possible by suppliers are similarly affected by the investment in specific clusters of practices. Shorter lead times benefit both retailers and manufacturers: our operations research model shows that manufacturers with shorter lead times must hold lower finished goods inventories to meet retail requirements than those with longer lead times.

The effect of deeper levels of investment on a unit's ability to meet retail service requirements does not seem to be strongly related to the cluster practices. Table 6 shows the percentage of goods delivered on time to retailers and the percent of orders delivered 100 percent com- 
plete to retailers. Although the results imply similar performance across all four groups, these accuracy-related measures must be interpreted in conjunction with replenishment findings. More innovative business units operating under substantially shorter order fulfillment time requirements are also able to maintain high service rates comparable to those units providing goods with longer order fulfillment and procurement time.

The impact of innovative practice investments on business unit performance is presented in the middle portion of table 6 . The results indicate that cluster practices have their most dramatic effects on operating profits. Measured as a percent of business unit sales, operating profits for all three models are approximately double those of the control group. The results are less consistent for the other measures of business unit performance, however; although Model 2 units show considerably higher gross margins and sales growth than does the control group.

The turn rate of finished good decreased for innovators. If all firms in the sample provided retailers with the same service levels (that is, lead times as well as order fulfillment and on-time delivery rates), one would expect the innovative firms' finished goods inventory turns to increase. Because, innovators provided similar order-fulfillment and on-time delivery rates on much shorter notice than did noninnovators, it is not surprising to see a small drop in their turn rates.

CONTROLling FOR OTHER FACTORS. Other factors associated with levels of investment in innovative practices and performance measures could explain the relationships described above. First, larger business units may be more able to afford innovative investments (all else being equal) than small units. If size is also correlated with performance, the results may in fact be traced to size rather than practice effects. In fact, the 1992 dollar sales volume of business units in the three innovative categories were higher than those in the control group.

Second, the degree of exposure to fashion-driven markets may also lead to spurious correlations. Because lean retailing focuses primarily on basic and fashion-basic products rather than on fashion-oriented products, correlations between the fashion category of supplier and performance could bias practice-performance estimates. Indeed, the bottom row of table 6 indicates that all three business unit models sold a higher percentage of goods in basic and fashion-basic categories than did the control group. 
Table 7. Relationship between Innovative Practices and Performance Measures, 1992

\begin{tabular}{|c|c|c|c|c|c|}
\hline \multirow[b]{2}{*}{ Dependent variables } & \multicolumn{3}{|c|}{$\begin{array}{l}\text { Innovative practices } \\
\text { (estimated coefficients) }\end{array}$} & \multirow[b]{2}{*}{$R^{2}$} & \multirow{2}{*}{$\begin{array}{l}\text { Degrees of } \\
\text { freedom }\end{array}$} \\
\hline & Model 1 & Model 2 & Model 3 & & \\
\hline \multicolumn{6}{|l|}{ Channel performance } \\
\hline $\begin{array}{l}\text { Order fulfillment time for } \\
\text { replenishment products (weeks) }\end{array}$ & $\begin{array}{r}-0.61 \\
(0.69)\end{array}$ & $\begin{array}{r}-0.90 \\
(1.17)\end{array}$ & $\begin{array}{r}-1.61 \\
(0.86)\end{array}$ & 0.10 & 50 \\
\hline $\begin{array}{l}\text { Procurement lead time-standard, } \\
\text { domestic source (days) }\end{array}$ & $\begin{array}{r}-68.58 \\
(20.64)\end{array}$ & $\begin{array}{r}-81.52 \\
(48.03)\end{array}$ & $\begin{array}{r}-48.11 \\
(27.50)\end{array}$ & 0.22 & 55 \\
\hline $\begin{array}{l}\text { Procurement lead time-shortest, } \\
\text { domestic source (days) }\end{array}$ & $\begin{array}{r}-34.07 \\
(13.42)\end{array}$ & $\begin{array}{c}-53.27 \\
(31.80)\end{array}$ & $\begin{array}{l}-23.74 \\
(20.16)\end{array}$ & 0.15 & 51 \\
\hline $\begin{array}{l}\text { Percentage of goods delivered } \\
\text { on time }\end{array}$ & $\begin{array}{c}0.50 \\
(2.82)\end{array}$ & $\begin{array}{c}1.67 \\
(6.03)\end{array}$ & $\begin{array}{r}-0.72 \\
(4.30)\end{array}$ & 0.08 & 63 \\
\hline $\begin{array}{l}\text { Percentage of orders delivered } \\
\text { complete }\end{array}$ & $\begin{array}{c}1.32 \\
(4.24)\end{array}$ & $\begin{array}{l}11.52 \\
(8.97)\end{array}$ & $\begin{array}{r}-0.29 \\
(6.36)\end{array}$ & 0.04 & 60 \\
\hline \multicolumn{6}{|l|}{ Business unit performance } \\
\hline Gross margins as percent of sales & $\begin{array}{c}0.06 \\
(2.69)\end{array}$ & $\begin{array}{c}8.72 \\
(5.82)\end{array}$ & $\begin{array}{c}0.16 \\
(3.63)\end{array}$ & 0.16 & 72 \\
\hline Operating profits as percent of sales & $\begin{array}{c}4.26 \\
(2.14)\end{array}$ & $\begin{array}{c}3.81 \\
(4.60)\end{array}$ & $\begin{array}{c}4.01 \\
(2.88)\end{array}$ & 0.12 & 69 \\
\hline $\begin{array}{l}\text { Sales growth between } 1988 \text { and } 1992 \\
\text { (in } 1988 \text { dollars) }\end{array}$ & $\begin{array}{r}-0.17 \\
(0.21)\end{array}$ & $\begin{array}{c}0.22 \\
(0.41)\end{array}$ & $\begin{array}{r}-0.36 \\
(0.30)\end{array}$ & 0.04 & 71 \\
\hline $\begin{array}{l}\text { Finished goods inventory } \\
\text { turns per year }\end{array}$ & $\begin{array}{l}-0.78 \\
(2.26)\end{array}$ & $\begin{array}{r}-2.46 \\
(4.51)\end{array}$ & $\begin{array}{r}-2.84 \\
(2.90)\end{array}$ & 0.02 & 64 \\
\hline
\end{tabular}

Source: Authors' calculations. Estimated coefficients are based on regression of dependent variables against three practice clusters and controls for business unit size and fashion content as measured in table 6 . (See text for definitions of practice clusters.) Coefficient values are measured against the base case of business units with no innovative clusters. Estimated standard errors of coefficients are in parentheses.

Table 7 presents the results of regression models that relate the three innovation clusters to performance measures, holding constant the effects of size (as measured by 1992 sales volume) and fashion content (as measured by the percent of sales in basic and fashion-basic categories). The effect of practices on performance continues to hold for the channel performance measures related to time. The negative signs of the coefficients for Models 1, 2, and 3 for replenishment speed and procurement lead times suggest that business units with innovative clusters have lower lead times than the control group after holding constant size and fashion content. The results show reductions of fortyeight to eighty-two days in standard lead time in comparison with the control group, even after holding constant the effects of business unit size and fashion content. The regressions do not indicate that cluster 
practices have significant effects on channel outcomes related to the percentage of goods delivered on time or completeness of orders.

The business unit performance results, controlling for size and fashion content, do not show statistically discernible effects. The sign and size of the coefficients relating operating profits to business unit innovation remain positive, however, and very large (and statistically significant in the case of Model 1 units). Operating profits as a percentage of sales in 1992 were 8.7 percent for the sample as a whole. The estimated coefficients ranging from 3.8 to 4.3 therefore suggest that innovative units earned 50 percent more operating profits, even after holding size and fashion content constant. (This difference is even more impressive when it is compared with the average operating profits of the control group.) Because operating profits are one of the clearest measures of an apparel firm's competitive success, these results imply that investment in even basic innovations substantially improves the viability of the investing firms.

If time to market continues to grow as an important competitive dimension for apparel suppliers, the results of table 7 imply that business units that invest in deeper levels of manufacturing investment will be better able to compete than counterparts who continue to organize production along traditional lines. If a larger percentage of retail customers moves toward the lean model, the competitive benefits from faster order fulfillment and lead time performance will increase further. Thus, although the statistical relationship between supplier practice and business unit performance is at this point weak, we would expect to find stronger associations as channel developments continue to evolve in the manner described in this article.

\section{Implications}

The information-integrated retail-apparel-textile channel is still in the early stages of development, with some participants in advance of others, but with the implications of its mature stages becoming more apparent. Using the data at hand (and informed by extensive industry observation and participation ${ }^{47}$ ), we see the following as being some of the major implications of the research at this stage of analysis:

47. The four authors cumulatively have worked with the retail, apparel, and textile 
1. The retail-apparel-textile channel appears to be driven by lean retailers who have taken the lead to require suppliers to meet their standards in information systems, bar-coding, EDI, and automated distribution centers. Moreover, the lean retailers practicing these methods have shown the greatest rates of growth since 1988 and are often projected to continue their greater growth rates.

2. The development of the integrated channel is cultivating a greater interest on the part of individual channel members in the performance of the channel as an integrated system. There is a greater recognition of and concern with channel interdependencies: firms are increasingly recognizing that they need to think about the full implications of their decisions on the channel when making internal operating decisions.

3. Changes in the retail-apparel-textile channel continue to induce transformations in internal manufacturing processes and in the roles of workers and managers. Thus, the control of traditional buyers and assistant buyers over retail ordering and pricing by experience and "feel" is yielding to the merchandise manager with point-of-sale and inventory information at the SKU level. Work processes in apparel assembly gradually are changing from the traditional bundle system in favor of modular methods. In textiles, which so far have been affected only to a small degree, the channel is compelling attention to smaller order size and quicker response to achieve flexibility. These changes within firms and their relationships are not autonomous developments instituted by independent enterprises, but changes driven by the information-integrated retailers and their customers.

4. With its capacity to handle a complex body of information with minimal time delays and at low operating costs, the channel provides the opportunity for greatly increased consumer choice and satisfaction-increased numbers of SKUs and fewer stock shortages-pushing the limits of individually customized apparel at low costs.

5. The channel introduces significant additional measures of performance beyond labor productivity - time to market, reduced costs of markdowns, reduced costs of stock shortfalls, and the accurate, timely

industries for more than forty years. For example, in 1980 Abernathy and Dunlop founded a major industry consortium, the Textile and Clothing Technology Corporation, known as (TC) ${ }^{2}$. Abernathy later took a two-year leave from Harvard to act as a managing director. (TC) $)^{2}$ has among its members major domestic textile firms, apparel manufacturers, and apparel retailers. 
performance of a variety of services. ${ }^{48}$ The development of the channel, even at the current stages, is focusing managerial attention on the costs of inventory, inventory replenishment practices, reliability of information, and time to market rather than on the historical factors of labor and transportation costs.

6. The costs of entry to the channel are increased by capital outlays for information systems and the built-in longer-term relations among enterprises in the channel that are less likely to be displaced by mere temporary price concessions. The development of the integrated channel has been associated with increased consolidation at its various stages.

7. Manufacturers perform a variety of services at rigorous standards for later stages in the channel-such as bar-coding, preparations for selling, distribution to particular distribution centers or retail outletsnot ordinarily included in the "output" of a manufacturing enterprise, complicating the meaning and comparisons of product and price and disadvantaging imports. In the same vein, manufacturers must make changes in their own internal operating practices to provide the required services to retailers without themselves incurring undue additional costs, especially in the form of inventory carrying costs.

8. Point-of-sale information and appropriate decision tools now allow retailers and manufacturers alike to manage products at the SKU level. Specifically, firms can target a desired level of service for each SKU and then set individual inventory target levels based on an SKU's demand uncertainty and target satisfaction rate.

9. Although retail has been the major catalyst for change in the apparel channel, a look across a broader range of industries suggests that the drivers of change may well be located elsewhere in the channel. For example, in the automobile channel, which extends from parts manufacturers through major car assemblers to dealers and their customers, the initiator of change may be the major producers who are changing relationships on both sides of their markets. Some channels may be genuine partnerships among a series of major players. Each channel may be expected to have its own dynamic.

10. As the domestic retail-apparel-textile channel reduces lead times

48. See Baily (1993) for a recent analysis of retail performance, focusing on labor and total factor productivity. 
to market, particularly with fashion and fashion-basic products, the comparative advantage of imports declines, despite lower wage costs and tariff reduction (including the elimination of tariffs brought about by international and national trade agreements). The domestic apparel sector for some products is not necessarily doomed by comparatively higher direct labor costs. In fact, a resurgence in certain sectors may be expected because of the innovative policies some manufacturers are now pursuing.

\section{Data Appendix}

One of the central objectives of this article and the larger study of which it is a part was to assemble detailed information at the level of the business unit concerning patterns and effects of changes resulting from major shifts in the volume, quantity, and cost of information in a production channel.

This type of enterprise requires information on the complete range of channel practices, beginning with retail practices, information systems, distribution practices, production practices, and relations with textile and other key suppliers. It also requires data on characteristics of the product markets for the businesses involved. To collect such detailed information has required the creation of an in-depth survey instrument that captures this comprehensive set of information.

\section{The Survey}

The questionnaire was developed through an iterative process of drafting, field testing, refinement, and further testing over a one-year period. The development process drew on a subset of ten key suppliers to a major U.S. department store chain representing a range of products in the men's and women's apparel industries.

The questionnaire is divided into the following eight modules to facilitate the process of distributing the survey section to appropriate company personnel: (1) overview (sales, cost structure, product lines); (2) the order fulfillment process; (3) manufacturing (cutting, assembly, and packaging); (4) domestic and international sourcing; (5) human 
resources; (6) supplier relationships; (7) sales, marketing, and product line development; and (8) distribution.

The size, detail, and confidential information requested in the questionnaire meant that a random, stratified sampling technique was not tractable. Instead, the survey effort required sponsorship and support from channel participants to achieve a sufficient number of responses. This sponsorship proved essential to achieving a reasonably high rate of response. Sponsorship of the survey included one major U.S. department store, one major mass merchandiser, and both of the major clothing unions - the Amalgamated Clothing and Textile Workers Union, and the International Ladies Garment Workers Union. The two retail sponsors of the questionnaire provided listings of their major suppliers and a cross-section of their smaller suppliers. The clothing unions provided lists of employers under contract with the unions in targeted product markets (see below).

This set of sponsors was chosen to achieve a representative sample of suppliers focusing on (but not limited to) ten retail-apparel-textile channel segments that were chosen to reflect different levels of past and prospective channel integration. For the men's industry, the chosen segments were suits, slacks, jeans, T-shirts, and dress shirts. For the women's industry, the segments were outerwear (coats and jackets), dresses, intimate apparel, sportswear slacks, skirts, and shorts, and blouses. Though the survey was sponsored by specific retailers or unions, each survey requested information from the business unit on its practices, characteristics, and performance for all retail customers. It therefore captured information concerning practices and performance regarding all of the business unit's product lines and retail customers.

\section{Response Rate and Representativeness}

A total of 435 companies were identified and sent questionnaires. Each company was instructed to answer separate questionnaires for each of its business units (see text for definition). Eighty-four companies completed the survey. Because many of the larger companies had multiple business units, 118 business unit questionnaires were received.

The representativeness of the sample for selected product groups is shown in table A-1. The table compares the total value of shipments for specific product groups as reported by the U.S. Department of 
Table A-1. Reported Sales by Product Category - Channel Survey Compared with U.S. Department of Commerce, 1992

\begin{tabular}{|c|c|c|c|}
\hline \multirow[b]{2}{*}{ Product category } & \multicolumn{2}{|c|}{ 1992, millions of dollars } & \multirow[b]{2}{*}{$\begin{array}{c}\text { Sample } \\
\text { as percent } \\
\text { of Commerce } \\
\text { estimate }^{\mathrm{c}}\end{array}$} \\
\hline & $\begin{array}{c}\text { Total dollar } \\
\text { volume in } \\
\text { sample }^{\text {a }}\end{array}$ & $\begin{array}{c}\text { Reported dollar } \\
\text { volume, } \\
\text { Commerce } \\
\text { Department }^{\mathrm{b}}\end{array}$ & \\
\hline Men's and women's jeans & 3,502 & 6,443 & 54 \\
\hline $\begin{array}{l}\text { Men's clothing } \\
\text { Suits } \\
\text { Slacks } \\
\text { Dress shirts }\end{array}$ & $\begin{array}{r}746 \\
1,997 \\
648\end{array}$ & $\begin{array}{l}2,450 \\
1,499 \\
1,173\end{array}$ & $\begin{array}{r}30 \\
133 \\
55\end{array}$ \\
\hline $\begin{array}{l}\text { Women's clothing } \\
\text { Outerwear } \\
\text { Dresses } \\
\text { Intimate apparel } \\
\text { Blouses }\end{array}$ & $\begin{array}{l}488 \\
637 \\
685 \\
226\end{array}$ & $\begin{array}{l}3,745 \\
5,443 \\
3,660 \\
3,618\end{array}$ & $\begin{array}{r}13 \\
12 \\
19 \\
6\end{array}$ \\
\hline $\begin{array}{l}\text { Apparel and other textile products } \\
\text { All apparel products }\end{array}$ & $\begin{array}{l}14,342 \\
13,792\end{array}$ & $\begin{array}{l}64,115 \\
46,442\end{array}$ & $\begin{array}{l}22 \\
30\end{array}$ \\
\hline
\end{tabular}

\footnotetext{
Source: Authors' calculations.

aSum of reported shipments in 1992 by business units for stated product categories.

${ }^{b}$ Based on 1991 Value of Product Shipments, U.S. Department of Commerce, Annual Survey of Manufacturers, Table I, pp. 2-9-2-10. Product category definitions are the following: men's and women's jeans 23252, 23395; men's suits 2311; men's slacks 2325I; men's dress shirts 23216; women's outerwear 2337; women's dresses 2335; intimate apparel 2341; 2342; women's blouses 2331.

cOur data classification at a product level and the SIC classification within the apparel industry (at the four- and five-digit level) are not identical in all product categories.

${ }^{\mathrm{d} E x c l u d i n g ~ n o n a p p a r e l}$ business units from sum.
}

Commerce with the sum of total sales per product category of survey respondents. The total volume of apparel shipped by business units (not including other textile products) in the sample equals $\$ 13.8$ billion in 1992. This compares with $\$ 46.4$ billion for the value of total shipments of apparel products in 1991.

The survey design was particularly successful in assuring response by major manufacturers in the targeted segments. For segments such as women's dresses and women's blouses, which are characterized by small manufacturers, our response rate was lower. As a result, the sample is biased toward larger firms and business units, making estimates of manufacturing innovation and performance skewed toward the practices of this group. 


\section{Comments And Discussion}

Comment by Timothy F. Bresnahan: This is a very interesting paper. It draws on the authors' impressive data collection effort and on their deep knowledge of the apparel industry. These assets let the authors explain the process by which new information technology and new business practices are transforming manufacturer-retailer relations. Although their analysis is limited to one particular industry, it has broader implications for the whole economy. Applications of networked information technology to commercial transactions are an important locus of contemporary technological progress. By analyzing in detail the forces at work in apparel manufacturing and retailing, Abernathy, Dunlop, Hammond, and Weil help us understand the broader economic forces behind the equilibrium pace of technological progress.

Two fundamental complementarities form the backdrop to this paper. The first is, in general terms, the innovational complementarity between information technology and the invention of new business practices. Information technology is general purpose and can be made useful in applications only after complementary invention. Specifically, this paper starts from the Milgrom-Roberts theory of organizations, in which communication and inventory are substitutes. Building new information technology systems delivers information about inventories, demand, and orders. For that information to be useful, there must be complementary changes in inventory control systems. More generally, information systems, for all the vast investment in their capabilities, are only as valuable as the use made of the information.

The second complementarity arises because the "organization"' to 
which the authors apply the theory is a marketplace. Lowering total systemwide inventory costs involves coordinated change by both buyers and sellers: "rapid replenishment." Avoiding retail inventory "stockouts" - a cost to the end consumer-similarly calls for coordination. Increasing the variety of choices available to consumers is another benefit of this same coordination.

The first thing I find interesting about this paper is the intersection of these two complementarities. I conjecture that they are systematic. Information technology calls for complementary change in the organization of economic activity; changing information structures change the way economic activity is coordinated. ${ }^{1}$ This, too, may be an example of an important contemporary direction of technological progress. The networked computer and the boundary of the firm may change together in many different markets.

The authors' analysis shows a very specific mechanism for coordinating systemwide technological progress. The exogenous driver was the invention of "lean retailing." Lean retailers differ from traditional stores in several ways, two of which are key to the argument of this paper. Lean retailers use superior information processing to achieve greater product variety, lower inventory cost, and less frequent stockouts than do other kinds of retailers. Correspondingly, lean retailers desire better information from manufacturers. Bar-coded products, for example, permit the retailers to be informed, the first step in information processing. Lean retailers also desire speed and reliability from manufacturers. If orders can be placed and filled quickly and reliably, the manufacturer inserts little noise into the retailers' inventory control problem. Lean retailers, well informed about their own inventory, can make very effective use of a reliable manufacturer. As a result, lean retailers have not only been successful competitively against other forms of retailers, but they have also imposed a new set of demands on manufacturers. ${ }^{2}$

Another innovative feature of lean retailing is new financial relationships with manufacturers. Lean retailers systematically shift the risk that a product will not sell by demanding contractual terms with man-

1. See Bresnahan and Saloner (1994) and Allen and Scott Morton (1994) for more on this general argument.

2. Bagwell and Ramey (1994) have a theory of lean retailing that explains, among many other features, the competitive success. 
ufacturers such as return rights. They reward timely deliveries and punish uncertainty with substantial financial penalties. They insist on an order-taking process that is swift and sure. These and other changed financial terms make a Wal-Mart purchase order into a frightening document.

How have apparel manufacturers responded to these changed demands? The authors' story is that competition among manufacturers provides an incentive to invent. They bundle information with goods (bar codes). They improve their external information processing (EDI order taking). They learn to use information from retailers (sales forecast systems). At the extreme, they may attempt the authors' "Model 3 ,' a complete overhaul of logistical systems based on new business systems and new information technology. But they do not change manufacturing processes much.

The authors' evidence for this conclusion combines statistical and institutional knowledge. Statistically, they divide manufacturers into four classes: from do-nothings through very innovative responders. They find better performance, on operational and economic measures, by the innovators. The nature of the innovative "clusters" is specifically described by the authors as varying degrees of accommodation to the needs of lean retailers. The differences in economic performance reflect the powerful competitive incentives to meet the demonstrated needs of customers (lean retailers).

The story here is one of disequilibrium. As with many "industry studies," one of the authors' purposes is to demonstrate the value of the innovative practices to laggard manufacturers who have not responded to the incentive for innovation. Despite the disequilibrium, the overall story seems quite convincing. The authors use their institutional knowledge to convince us of their interpretation of the statistically measured performance differences.

At least two important general lessons can be drawn from this industry's experience. The first concerns the economic process by which the coordinated technical progress went forward. A changed information-processing capability was invented by demanders; it was privately profitable for them even without a complementary response from sellers. Competition among sellers then provided the private incentive for the complementary response.

As with any positive feedback coordination story, this analysis is 
fundamentally ambiguous. The authors see the glass as half full. For the industry at hand, the positive feedback process has been started and is continuing. To be sure, part of the message is that laggard manufacturers could increase performance by catching up. Broadly, however, the authors are confident that this coordinated, information technologyenabled progress will reduce the competitive disadvantage of U.S. apparel manufacturers.

The key appears to have been the invention of lean retailing, which provided an impetus to the entire system. In a paper dealing with interactions between demanders and suppliers in a wide variety of markets, Tom Hubbard, Garth Saloner, and I have called this the "gorilla effect." The presence in one side of the market of an important enough firm to drive the process starts the coordinated innovation.

Not all gorillas are buyers, but they all are capable of providing incentives to the other side of the market. The role played by lean retailers has been played elsewhere by the Health Care Finance Administration in electronic payment systems for health insurance and by the Ford Motor Company in dealer inventory systems. These examples underline the ambiguity of the evidence. It may be that the successful coordination is, as the authors suggest, a message about the future comparative advantage of U.S. industries. Another interpretation consistent with the evidence at hand emphasizes the relative scarcity of gorillas as powerful as lean retailers. In this darker view, the coordination opportunities are surely present, but in many contexts actual coordination may be held up. What, in general then, will determine the circumstances in which coordination will succeed or fail? The authors' analysis gives some valuable clues.

The first clue is the value of timely and assured information. The authors examine an industry-clothing retailing-in which the use of information to control inventory costs is central. The information is spread out over geographical space and must be assembled rapidly. Newly available information technology makes practical solutions to this problem feasible. The replacement of paper, FAX, and telephonebased communications (all heavy users of expensive white-collar labor) by computer-based communications should be expected whenever the advantages of communications (lower inventories, fewer stockouts) overcome the barriers to coordination.

The second clue is that the distribution of rents is key to the coor- 
dination problem. The authors note how innovation on the retail side of this market shifted the distribution of rents, creating a newly competitive upstream sector. The kinds of change they describe seem likely to shift rents systematically. In the present instance, "lean retailing", appears to have been privately profitable for stores even if manufacturers did not accommodate the practice. Coordination problems with rent distribution are hard; coordination with one side exogenously moving forward is easy.

It has been widely thought that textile manufacturing in the United States is a dying industry, that the United States is simply not a costeffective place in which to locate such industrial activity. The authors believe that the industry may be viable, in part because of the developments they chronicle. This argument is worth understanding in detail. It relocates the key competitive performance dimension for a textile manufacturer from plant cost to management of inventory and service. That shift, driven by technological progress, moves the industry toward comparative advantages of the industrialized nations, especially the United States. Proximity to large markets, technological sophistication, and, I would add, flexibility in the institutional arrangements of commerce become competitively valuable. This story, if true and exemplary, is important.

Comment by B. Peter Pashigian: This paper provides a very interesting survey of recent technological advances in the apparel industry that have increased the incentives for information sharing among the firms within a vertical channel. The authors present new survey results that measure the diffusion of these technological changes and the subsequent changes in firm behavior and practices. The relation between technical change, be it in manufacturing or retailing, and induced changes in distribution and pricing practices is a long neglected subject, and this paper is one of the few that treats this challenging subject.

Historically, the U.S. clothing industry has been a vertically unintegrated channel. Final consumers demand a wide variety of clothing products supplied by retailers, among which are department stores such as Bloomingdales and Marshall Field; national chains such as Sears and J.C. Penney; the emerging specialty stores such as the Gap and the Limited, and mass market discounters such as Wal-Mart and Kmart; and many other smaller apparel stores. Retailers forecast future de- 
mands and order merchandise well in advance of the season from domestic and foreign apparel manufacturers who cut, sew and, assemble garments. Depending on the type and price of the product, retailers place orders anywhere from two to eighteen months in advance of the season. The fabric is supplied by textile firms who spin raw materials into yarn and weave the yarn into unfinished fabrics. Because firms specialize by operation or function, market transactions between stages are more the rule than is vertical integration. Moreover, a highly specialized world market has evolved, with garments sent to different countries where different operations are performed.

The authors discuss how technological advances have affected firms at each stage within this channel. Among the central technological innovations they consider are the growing use of bar-code scanning equipment, which lowers the cost of identifying products and packages; electronic data interchange, which has reduced the cost of communicating consumption and other data within the vertical chain; and automation of distribution operations, which improves identification and sorting capabilities. The central thesis is that these changes foster the development of lean retailing, reduce retailer inventories, and permit apparel and textile firms to respond more rapidly to unexpected shifts in consumer preferences for colors, silhouettes, and fabrics.

According to the authors, lean retailing permits retailers to order minimal quantities at the beginning of the season and then to reorder additional quantities as demand uncertainty is resolved. This flexibility is not a free good. Apparel and textile firms must replenish the retailer inventories with shorter lead times if lean retailing is to be successful. To do this, they must invest in information gathering to forecast consumer demands more accurately and in more flexible production facilities. An unanswered question is why apparel and textile firms can forecast consumer demands more accurately than retailers. I would like to see a more thorough explanation in the paper of why the new technology gives the apparel and textile firms a comparative advantage in resolving consumer demand uncertainty. Is it because manufacturers have more sales data than individual retailers do? But was this not true before as well as now? Have there been other technological changes that make flexible production less costly now than before and that encourage the adoption of lean retailing?

Survey results indicate that national chains and mass merchandisers 
order more frequently than do other retailers. These stores sell a larger fraction of basic goods than do department and specialty stores, which place greater emphasis on fashion clothing. This finding indicates that the adoption of lean retailing depends on the type of garment being sold by the retailer. Table 2 of the authors' paper shows the number of distinct seasons increased from 2.9 in 1984 to 3.7 in 1992 for fashion goods but increased only modestly, from 2.4 seasons in 1984 to 2.6 in 1992 , for basic products. The frequency of product introductions has increased more in the fashion segment of the market. These estimates imply that the average length of season is around three months in the fashion market-a short window of opportunity for firms to reorder merchandise. It probably takes two weeks to a month at the beginning of the season just to determine which colors and styles are the fashion hits of the current season before the retailer can even place a reorder. This suggests that lean retailing is less likely to be adopted in women's and men's fashion clothing markets. In addition lean retailing is less likely to be adopted for products that require longer lead times. If a garment must be shipped to several countries while different operations are performed, a retailer cannot expect to reorder and so must stock the garment at the beginning of the season. The adoption of lean retailing may require less intercountry production if a rapid response is to be achieved.

What implications do the authors draw from the adoption of lean retailing? They argue that retailers and apparel manufacturers will invest more in information technologies that lower the cost both of transmitting information and of transferring products from apparel manufacturer to distribution points of the retailer. Further, these investments should be undertaken by business units that have adopted lean retailing.

To perform their empirical tests, the authors obtain survey information from a sample of 118 business units of 84 companies, a Herculean undertaking, seldom undertaken by academics. The sample is somewhat biased toward inclusion of larger business units and therefore toward firms that supply men's rather than women's apparel. Business units are classified into those that have high or low rapid replenishment rates, that is, by the frequency of ordering. This important decision essentially sorts the business units in their sample into two groups. On the one hand are the business units that ship frequently to national chains and mass or discount distributors. On the other hand are the department 
stores, specialty stores, and mail order firms that reorder less frequently. Throughout the analysis the independent variable is the 1992 replenishment rate, but it is an endogenous variable because it is determined by the response of the firms to these technological changes. It would have been preferable to use the initial 1988 replenishment rates as a predetermined variable in the regression analysis and then determine if units with higher 1988 replenishment rates have superior performance or a higher probability of adopting the new technology. Sorting firms by replenishment rate also means high replenishment business units will be units that place less emphasis on fashion products and more on semi-basic or basic garments. Because lean retailing is less likely to be successful for retailers merchandising fashion goods, one can expect to find retailers and their suppliers that sell basic goods to be more receptive to lean retailing, willing to make the necessary investments and have shipments with high replenishment rates. In future work the authors could determine if the adoption of this new technology resulted in more frequent reorder rates and if business units that shipped basic goods were more likely to shift toward more frequent reorder rates.

In their empirical work the authors test for a significant difference between the means of different dependent variables of business units with high versus low replenishment rates. The authors present a plethora of results. I will mention only a few. First, they show a growing adoption between 1988 and 1992 of bar-code technology, electronic data interchange, and the interchange of point of store sales information by apparel suppliers. The authors, however, find only a statistically significant effects increase over time for two of five measures for distribution practices in their regression analysis. These tests do not make a strong case that this new technology has had a large effect on distribution practices, and little has changed so far with regard to the practices of textile suppliers.

When the authors distinguish between business units with high and low replenishment rates in 1992, they do find some significant differences. Units with higher replenishment rates in 1992 were more likely to adopt the bar-code technology, share more POS information with their suppliers, and invest more in information systems capital and in distribution centers. They also find that units with high replenishment rates ship larger lot sizes of basic goods, a finding that suggests that 
lean retailing is more prevalent in the retailing sectors where basic goods are sold. The authors also find some performance differences. At some point the authors should reconcile the absence of time series performance effects with the cross-sectional findings that indicate business units with high replenishment rates are more receptive to the new technology and perform differently.

The authors go on to determine how the adoption of lean retailing affected the performance of business units. They sort firms into four groups based on how many of the forty innovative practices the business unit adopted. Then they determine if the units in the higher innovative categories performed better than the units in the control group. They find that order fulfillment times are lower and lead times are shorter for the business units in the innovative groups. Firms that adopted innovative practices did have higher profits as a percentage of sales but not higher gross margins relative to sales. The regression results are more qualified, however. These preliminary results do not demonstrate a systematic performance difference between high and low innovative business units.

I would like to add several more general comments and suggestions.

1. The period between 1988 and 1992 is comparatively short and, unfortunately, includes a recession that undoubtedly reduced the demand for fashion goods relatively to the demand for basic goods. Because the authors find that firms selling basic products are more likely than other retailers to adopt lean-retailing techniques, it may be dangerous to extrapolate from the time series results for this period, a comparatively short and hardly settled one.

2. The dollar volumes of the business units in the sample indicate women's clothing firms are underrepresented in the sample. Because women's clothing is more fashion oriented, the results may be somewhat unrepresentative of the total apparel market. If the sample is large enough, the authors might distinguish between women's and men's clothing and see if significant differences exist in manufacturers' use of lean retailing and the new technology.

3. The authors need to supplement their survey results, as useful as they are, with other market evidence. For example, is there any evidence that lean retailing has had an effect on the scale of discounting at retail? The authors can track discounting propensities for this period in Merchandising and Operating Results of Department Stores and 
Table 1. Inventory-Sales Ratios for Selected Retailing Industries, 1988-1993

\begin{tabular}{lccr}
\hline Group & 1988 & 1993 & $\begin{array}{r}\text { Percent } \\
\text { change }\end{array}$ \\
\hline All retailing (excluding & & & \\
$\quad$ automobiles) & 1.50 & 1.46 & -1.3 \\
$\begin{array}{l}\text { Department stores } \\
\begin{array}{l}\text { Apparel and accessory } \\
\quad \text { stores }\end{array}\end{array}$ & 2.37 & 2.44 & 3.0 \\
\hline
\end{tabular}

Source: Author's calculations based on data from Bureau of the Census, Retail Trade, various issues, U.S. Department of Commerce.

Specialty Stores, as reported by the National Retail Merchants Association for department and specialty stores. If the authors' contentions are correct and lean retailing reduces forecasting errors, then we should observe a decline in discounting. This publication also reports stock age, the percentage of merchandise held by department stores that is less than six months old. Better yet, the authors might exploit their contacts with retailers and investigate changes in retail markdown propensities by comparing lines of retail business where the new technology was and was not adopted.

Another possible test would determine if inventory-sales ratios declined more rapidly in apparel retailing because of the adoption of lean retailing. The theory suggests that inventories should be lower relative to sales at least at the beginning of the season. The U.S. Bureau of Census reports inventory-sales ratios by retailing industry, so it is possible to track changes in inventory behavior of retailers. I checked recent trends in industry inventory-sales ratios as reported by the Bureau of Census from 1988 to 1993, two reasonably prosperous years. Table 1 shows that the ratio declined by 1.3 percent for all retailing (excluding autos) over this period but increased by 3.0 percent in the department store group which includes mass distributors such as Wal-Mart. The ratio did not change for apparel and accessory stores. If lean retailing is being adopted by more and more retailing firms in the apparel area, it has not as yet been reflected in reductions in relative inventory-sales ratios.

4. If it is possible, the authors should check to see if performance differences that they observed between high and low replenishment business units did not already exist before 1988. For example, the firms that subsequently adopted more innovative practices could have been 
Figure 1. Monthly Price Relatives for Women's Apparel, Fall-Winter Season, 1947-1988

Monthly Price Relative

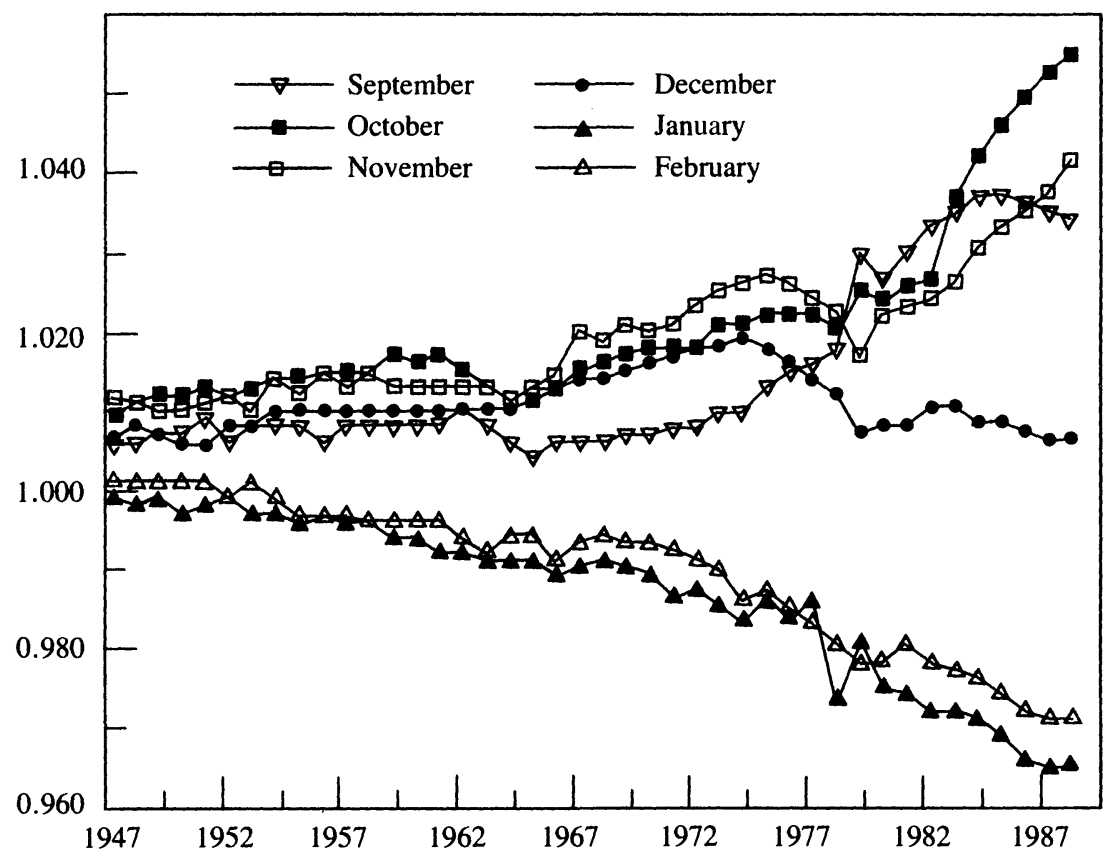

Source: Author's calculations based on data from the Bureau of Labor Statistics, U.S. Department of Labor.

performing better even before they adopted these practices. Hence, the adoption of innovative practices need not be the primary cause of their superior performance.

5. If the adoption of lean retailing implies that buyers will make fewer forecasting errors, that should be reflected in a decline in retail discounting at the end of the season. January and February are the traditional discount months where stores sell remnants of the fall-winter season, and July and August are the corresponding months for the spring-summer months, so we should see less discounting at the end of seasons. One way to test this hypothesis is to determine if the seasonal variation of apparel prices has declined in recent years or at the very least stopped increasing. Figure 1 shows that the seasonal swing in women's apparel prices during the fall-winter season began increasing 
in the mid-1960s. The monthly price relative is the ratio of the unadjusted to the seasonally adjusted prices for women's apparel and is plotted for each month from September to February since 1947. The figure shows that women's retail apparel prices fluctuate more during the fall-winter season now than they used to. If the adoption of the bar code technology is a quantitatively important change, we should begin to see less discounting at the end of seasons. It would be interesting to know if the seasonal swing in retail apparel prices decreased from 1988 to 1992.

6. It would be a mistake to come away from this paper thinking that technological change always reduces forecasting errors. As the authors point out, it can reduce forecasting errors. But technological change can also increase forecasting errors and make the life of a retailer more difficult. The increased seasonal swing in retail apparel prices portrayed in figure 1 reflects greater end-of-season discounting since the late sixties. I believe this has come about because stores are offering consumers an increasing variety of styles and fashions. The rise of the computer has transformed the fashion industry drastically by reducing setup costs of changing designs when weaving or knitting fabrics. Before the arrival of the computer, a knitting machine might have been down a whole day just to change the design on a sweater. Only minutes are needed to program a design change with a computer. The cost of producing fashion goods has fallen relative to the cost of producing basic goods. Hence more designs and colors are now being produced. This greater product variety increases uncertainty about what consumers will pay for goods and results in more forecast errors and ultimately larger markdowns at the end of seasons. Unlike the authors' case, in this case technological change can reduce forecast accuracy.

General Discussion: Much of the discussion was centered around statistical and measurement issues. Noting that the authors had analyzed a large number of possible statistical relationships, Zvi Griliches argued that some of their significant $t$-ratios might have resulted simply from chance. He suggested that the authors perform additional, more sophisticated statistical techniques to bolster their conclusions. Pointing out that other research has shown that larger plants are more likely than smaller ones to adopt technical innovations, Brad Jensen said that the authors should supply additional descriptive statistics on average busi- 
ness unit size for each of their categories of analysis. He suggested that systematic size differences between, for example, business units facing high replenishment pressures and those facing low pressures might provide an alternative explanation for the authors' results. Frederick Abernathy answered that firms using the highest levels of information technology vary in size by about two orders of magnitude, with gross sales ranging from $\$ 20$ million to $\$ 2$ billion, and that the largest firms are composed of several business units.

Peter Reiss suggested that the authors clarify which of their findings are specific to the apparel industry and which might be applicable to others as well. He argued that the use of information to reduce inventory loss, for example, should be occurring in other industries, such as book publishing. In response, Abernathy said, that although the apparel industry had copied some of its bar-coding techniques from the food industry, the former initially used bar coding only for inventory control. More recently, however, the food industry has begun to adopt this practice as it has become less expensive to enter bar codes into checkout cash registers. 


\section{References}

Allen, Thomas J., and Michael S. Scott Morton, eds. 1994. Information Technology and the Corporation of the 1990s: Research Studies. Oxford University Press.

Bagwell, Kyle, and Garey Ramey. 1994. "Coordination Economies, Advertising, and Search Behavior in Retail Markets.' American Economic Review 84 (June): 498-517.

Baily, Martin Neil. 1993. "Competition, Regulation, and Efficiency in Service Industries." Brookings Papers on Economic Activity: Microeconomics 2: 71-159.

Bental, Benjamin, and Benjamin Eden. 1993. "Inventories in a Competitive Environment." Journal of Political Economy 101 (October): 863-86.

Blanchard, Olivier J. 1983. "The Production and Inventory Behavior of the American Automobile Industry." Journal of Political Economy 91 (June): 365-400.

Blinder, Alan S. 1982. "Inventories and Sticky Prices." American Economic Review 72 (June): 334-48.

— 1992. "Maintaining Competitiveness with High Wages." International Center for Economic Growth, Occasional Paper 26. San Francisco: ICS Press.

Bresnahan, Timothy, and Garth Saloner. 1994. 'Large Firms' Demand for Computer Products and Services: Competing Market Models, Inertia, and Enabling Strategic Change." Stanford University.

Bureau of the Census 1994. County Business Patterns, 1991. CBP-91-1. U.S. Department of Commerce. February.

Bureau of Labor Statistics. U.S. Department of Labor. 1991. "Employment by Industry." Monthly Labor Review 114 (November): 59.

1992. Outlook 1990-2005. Bulletin 2402. May.

Chandler, Alfred D. Jr. 1977. The Visible Hand: The Managerial Revolution in American Business. Belknap Press.

- 1990. Scale and Scope: The Dynamics of Industrial Capitalism. Belknap Press.

Chaykowski, Richard P., Terry Thomason, and Harris L. Zwerling. 1994. "Labor Relations in American Textiles." In Contemporary Collective Bargaining in the Private Sector, edited by Paula B. Voos, 373-410. Madison, Wis.: Industrial Relations Research Association.

Cline, William R. 1987. The Future of World Trade in Textiles and Apparel. Washington: Institute for International Economics.

Grossman, Sanford J., and Oliver D. Hart. 1986. "The Costs and Benefits of Ownership: A Theory of Vertical and Lateral Integration." Journal of Political Economy 94 (August): 691-719. 
Hammond, Janice H., Tang, Z.-Bo, and Frederick H. Abernathy. 1994. "Design and Scheduling of Apparel Manufacturing Systems with Both Slow and Quick Production Lines." Harvard University.

Holt, Charles, and others. 1960. Planning Production, Inventories, and Work Force. Prentice-Hall.

Hotelling, Harold. 1933. "Analysis of a Complex of Statistical Variables into Principal Components.' Journal of Educational Psychology 24 (September): 417-41; continued in (October): 498-520.

Johnston, Russell, and Paul R. Lawrence. 1988. "Beyond Vertical Integration: The Rise of the Value-Adding Partnership." Harvard Business Review (July-August): 94-101.

Lee, Hau, Paddy Padmanabhan, and Seungjin Whang. 1994. "Information Distortion in a Supply Chain: The Bullwhip Effect." Stanford University. January.

Milgrom, Paul and John Roberts. 1988. "Communication and Inventories as Substitutes in Organizing Production.' Scandinavian Journal of Economics 90 (3): $275-89$.

1990. "The Economics of Modern Manufacturing: Technology, Strategy, and Organization." American Economic Review 80 (June): 511-28.

Office of Technology Assessment. 1987. The U.S. Textile and Apparel Industry: A Revolution in Progress: Special Report. U.S. Congress.

Pashigian, Peter B. 1988. "Demand Uncertainty and Sales: A Study of Fashion and Markdown Pricing." American Economic Review 78 (December): 93653.

Sako, Mari. 1992. Prices, Quality, and Trust: Inter-Firm Relations in Britain and Japan. Cambridge University Press.

Standard and Poor's Industry Surveys. 1994. Retailing: Current Analysis. (September 8): R61-R78.

Sterman, John D. 1989. "Modeling Managerial Behavior: Misperceptions of Feedback in a Dynamic Decision Making Experiment." Management Science 35 (March): 321-39.

Stone, N.I. 1938. "Systems of Shop Management in the Cotton-Garment Industry."' Monthly Labor Review (June): 1299-1330.

Williamson, Oliver E. 1979. "Transaction Cost Economics: The Governance of Contractual Relations." Journal of Law and Economics 22 (October): 233-61. 